Article

\title{
Long-Term Thermal Aging of Modified Sylgard 184 Formulations
}

\author{
Zachary Brounstein ${ }^{1,2}$, Jianchao Zhao ${ }^{3}$, Drew Geller ${ }^{1}$, Nevin Gupta ${ }^{1}$ and Andrea Labouriau ${ }^{1, *}$ \\ 1 Los Alamos National Laboratory, Los Alamos, NM 87545, USA; zrbrounstein@lanl.gov (Z.B.); \\ dgeller@lanl.gov (D.G.); nevin5@lanl.gov (N.G.) \\ 2 Department of Nanoscience and Microsystems Engineering, University of New Mexico, \\ Albuquerque, NM 87131, USA \\ 3 Department of Chemical Engineering, University of Michigan, Ann Arbor, MI 48109, USA; jczhao@umich.edu \\ * Correspondence: andrea@lanl.gov
}

Citation: Brounstein, Z.; Zhao, J.; Geller, D.; Gupta, N.; Labouriau, A. Long-Term Thermal Aging of Modified Sylgard 184 Formulations Polymers 2021, 13, 3125. https:// doi.org/10.3390/polym13183125

Academic Editor: Kumkum Ahmed

Received: 20 August 2021

Accepted: 14 September 2021

Published: 16 September 2021

Publisher's Note: MDPI stays neutral with regard to jurisdictional claims in published maps and institutional affiliations.

Copyright: (c) 2021 by the authors Licensee MDPI, Basel, Switzerland. This article is an open access article distributed under the terms and conditions of the Creative Commons Attribution (CC BY) license (https:/ / creativecommons.org/licenses/by/ $4.0 /$ )
Abstract: Primarily used as an encapsulant and soft adhesive, Sylgard 184 is an engineered, highperformance silicone polymer that has applications spanning microfluidics, microelectromechanical systems, mechanobiology, and protecting electronic and non-electronic devices and equipment. Despite its ubiquity, there are improvements to be considered, namely, decreasing its gel point at room temperature, understanding volatile gas products upon aging, and determining how material properties change over its lifespan. In this work, these aspects were investigated by incorporating well-defined compounds (the Ashby-Karstedt catalyst and tetrakis (dimethylsiloxy) silane) into Sylgard 184 to make modified formulations. As a result of these additions, the curing time at room temperature was accelerated, which allowed for Sylgard 184 to be useful within a much shorter time frame. Additionally, long-term thermal accelerated aging was performed on Sylgard 184 and its modifications in order to create predictive lifetime models for its volatile gas generation and material properties.

Keywords: Sylgard 184; PDMS; thermal aging; gas evolution; accelerated aging; gel point

\section{Introduction}

Sylgard 184 is commercial high-performance silicone elastomer comprised of poly(dimethyl siloxane) (PDMS) and other silicon-based compounds originally developed by Dow Corning Corporation. Due to its optical transparency [1], thermal stability [2], mechanical advantages [3], and resistance to oxidation and hydrolysis [4], Sylgard 184 has been used as a potting material in numerous applications, spanning microelectromechanical systems (MEMS) [5,6], electronic devices, and aerospace adhesives [7]. It is fabricated by mixing a prepolymer base (Part A), also referred to as the elastomer resin, and curing agent (Part B), also referred to as the hardener [8]. What separates Sylgard 184 from PDMS is that there are additional components other than the siloxane units in parts A and B. Besides siloxane units, the prepolymer base comprises a vinylated and methylated surface-modified silica filler component and vinyl-terminated and branched siloxane components [9]. The curing agent also contains linear and cyclosiloxanes, the modified silica filler, and platinum to catalyze the hydrosilylation reaction mechanism responsible for forming the crosslinked PDMS network. The hydrosilylation reaction entails Si-H groups interacting with vinyl moieties in the presence of a catalyst [10-12] to form new bonds between the two chemical groups. Once both parts A and B are mixed together, the polymer undergoes crosslinking and cures in $48 \mathrm{~h}$ with full mechanical properties being demonstrated after a week [13]. Although the standard mixing ratio of 10:1 resin to hardener produces a material that exhibits hyperelasticity, high surface adhesion, and low Young's modulus, these properties can be altered for a variety of applications by increasing or decreasing the mixing ratio [13,14]. In addition to altering the mixing ratio, many complementary products exist for changing 
viscosity and curing times [15]. Accelerating the curing time is routinely performed by curing at higher temperatures [16-18]; however, for many applications this approach is not feasible because the components surrounding Sylgard 184 can be heat-sensitive. One available commercial product, DOWSIL 3-6559 Cure Accelerator, which includes a platinum catalyst and oligomeric, vinyl-terminated PDMS, can accelerate room-temperature curing of silicone rubbers. Although this commercial product exists, it is desirable to tune the kinetics of the hydrosilylation reaction with controlled additions of either well-defined vinyl or silane moieties to accelerate room-temperature curing.

In addition to understanding and altering the rate at which Sylgard 184 cures, evaluating the material performance over its lifetime is necessary for its safe and predictable use. Because of its ubiquity and wide range of applications, Sylgard 184, often referred to in the literature as PDMS, has been extensively studied with regards to its material properties, including how its behavior changes when combined with fillers and other polymers to make composites; these span many cutting-edge materials such as shape memory elastomers [19-24] and wearable electronics [25,26]. Despite the plethora of research conducted on PDMS and PDMS composites, there has been much less focus on investigating how the performance of Sylgard 184 changes over time. Some work examining how aged Sylgard changes includes thermally aging chemically modified Sylgard 184 [27], UV-aging PDMS insulation [28], thermally aging resin-filled PDMS elastomers [29], humidity-aging siloxane foams [30,31], and gamma irradiation-aging silicones [32]. Natural and induced aging can lead to device or application failure and could potentially introduce new hazards. One prevalent example involves volatile products from siloxane compounds. Although it is well-known and documented within the literature and industry that hydrogen generation from silicon compounds could pose serious direct and indirect hazards [17,33,34], there have been no long-term studies quantitatively measuring hydrogen generation from PDMS. Furthermore, studies have not evaluated whether other volatiles are generated in the aging of PDMS. Instead, studies that probe volatile product generation of silicone compounds focus on induced thermal decomposition [35-41]. Additionally, while volatile gas evolution may pose a serious problem, of prime concern is how the material itself changes over its lifetime; yet, there is much more literature on short-term behavioral and property changes. Thus, volatile product generation, taken together with the long-term behavior of PDMS, represents a significant gap in knowledge and the literature.

The present study is an investigation aiming to solve the three problems that have been previously described. First, Sylgard 184 was modified with well-known compounds to accelerate the curing reaction at room temperature. Our team had previously worked on room-temperature curing of Sylgard 184, which resulted in finding that incorporating $0.1-0.3 \mathrm{wt} \%$ Ashby-Karstedt catalyst accelerated its curing time and improved its mechanical properties [13]. Additionally, we found that the incorporation of tetrakis (dimethylsiloxy) silane (TDS) (a siloxane-based silane crosslinking agent) was able to reduce the curing time significantly. Four different formulations of Sylgard 184, comprising a control and combinations of the Asbhy-Karstedt catalyst and TDS, were studied for their curing time and other initial properties. Second, thermal accelerated aging was performed on the formulations in isothermal conditions from $25{ }^{\circ} \mathrm{C}$ to $90{ }^{\circ} \mathrm{C}$ for up to twelve months. Long-term material performance was evaluated and modeled to predict behavior based on this data. Third, headspace analysis was conducted on two of the formulations to determine which volatile components were being generated during aging. Inert and oxygen-rich atmospheres were used to probe how the surrounding environment might affect the materials' properties. Chemical, mechanical, and thermal properties were investigated to produce a thorough assessment of the lifetime performance of Sylgard 184. Thus, this study is a novel investigation into the comprehensive, long-term aging behavior of Sylgard 184 and its fast-curing formulations. 


\section{Materials and Methods}

\subsection{Materials}

Dow SYLGARD ${ }^{\mathrm{TM}} 184$ Silicone Elastomer was formulated from a base agent and curing agent, both of which were supplied by Ellsworth. Ashby-Karstedt catalyst (platinumcyclovinylmethyl- siloxane complex; $2 \% \mathrm{Pt}(0)$ in cyclomethylvinylsiloxanes) was supplied by Gelest. Tetrakis (dimethylsiloxy) silane (TDS) was supplied by Gelest. Ultra-high purity nitrogen was supplied by Airgas. HPLC-grade chloroform and toluene were supplied by Thermo Fisher Scientific.

\subsection{Sylgard 184 Formulations}

A ratio of 10:1 w/w was used for the base agent and curing agent, respectively, to make the standard Sylgard 184 framework. All samples were made from the same batch. It should be noted that the formulations must be made in a specific order: the TDS crosslinker and Ashby-Karstedt catalyst, when used in the formulations, are added to the elastomer base and curing agent, respectively. This is because of what they resemble in Parts A and B; TDS is chemically similar to the branched silane found in Part A while the Ashby-Karstedt catalyst is chemically similar to the cyclosiloxane and Pt found in Part B. Incorporating the additional compounds into dissimilar parts will result in the hydrosilylation reaction occurring before the prepolymer base and curing agent are added, yielding a non-uniform elastomer matrix. The TDS and Ashby-Karstedt catalyst compounds were always added in proportion to the total mass of the standard Sylgard 184 framework. For the samples made in this study, the order (if the component was present) went: (1) TDS; (2) Elastomer base; (3) Curing Agent; and (4) Ashby-Karstedt catalyst. This present study investigates the material properties of four different formulations of Sylgard 184 that are listed in Table 1. Once all the constituents were added together, the mixture was placed in a THINKY ARV310 planetary mixer for two minutes at $2000 \mathrm{rpm}$ at a vacuum of $0.2 \mathrm{psi}$. After pouring the resulting blend into the desired mold, the polymer solution was cured in a $25^{\circ} \mathrm{C}$ oven for one week.

Table 1. The formulations of Sylgard 184 used in this study.

\begin{tabular}{ccc}
\hline Formulation Name & $\mathbf{w t} \%$ TDS & $\mathbf{w t} \%$ Asbhy-Karstedt Catalyst \\
\hline Control & 0 & 0 \\
Opt2 & 0 & 0.2 \\
1pt1 & 1 & 0.1 \\
1pt2 & 1 & 0.2 \\
\hline
\end{tabular}

\subsection{Thermal Accelerated Aging}

Determination of long-term material performance and behavior of polymers has been investigated using the concept and methodology of thermal accelerated aging [42-48]. After samples had reached their gel point and fully cured, which was determined by rheology and the technical data sheet, respectively, in a $25^{\circ} \mathrm{C}$ oven, they were grouped to be thermally aged. Six ovens were kept isothermal at $25^{\circ} \mathrm{C}, 50^{\circ} \mathrm{C}, 60^{\circ} \mathrm{C}, 70^{\circ} \mathrm{C}, 80^{\circ} \mathrm{C}$, and $90^{\circ} \mathrm{C}$. Samples that did not have TDS added (Control and 0pt2 formulations) were placed in sealed canisters. Each non-TDS formulation was placed in an individual canister per oven above $25^{\circ} \mathrm{C}$, which made up ten canisters. Samples were placed such that they did not have contact with the metal canisters. After they were securely sealed and fastened, the canisters had their air evacuated, creating a vacuum around $10^{-3}$ torr, and filled with ultrahigh purity nitrogen to around 600 torr. An additional Control canister and 0pt2 canister went through the same process as described above, with the exception that these two canisters were kept in air at atmospheric pressure and placed in the $90{ }^{\circ} \mathrm{C}$ oven. Enough specimens were placed in the ovens so that they could be removed after aging for two, five, and twelve months. As an experimental note, two sample canisters for the 12-month aging Control $\left(60^{\circ} \mathrm{C}\right.$ and $\left.70{ }^{\circ} \mathrm{C}\right)$ leaked on their way to be analyzed and no mass spectrometry data could be recovered. Plots for the Control omit these two data points. 


\subsection{Chemical Characterization Techniques}

Rheological measurements were taken with a TA Instruments Discover HR-2 Rheometer. For gel point determination, a $25 \mathrm{~mm}$ parallel plate attachment was used with a gap height of $1000 \mu \mathrm{m}$. With a strain rate of $4 \%$ and a frequency of $10 \mathrm{rad} / \mathrm{s}$, the system was kept isothermal at $25^{\circ} \mathrm{C}$ and the storage and loss moduli were measured as a function of time. The gel point, or working time, of the formulations was determined as the time elapsed from the beginning of the experiment until a crossover of the moduli was observed, where the loss modulus fell below the storage modulus.

Fourier transform infrared (FTIR) spectroscopy was used to determine the functional groups of the materials. FTIR was performed using a ThermoScientific Nicolet iS50 FTIR with an average of 32 scans at a resolution of $4 \mathrm{~cm}^{-1}$ between $4000-525 \mathrm{~cm}^{-1}$. The measurements were performed in attenuated total reflection (ATR) mode with a diamond crystal reference. A background spectrum was taken before each measurement.

Contact angle measurements were used to determine how hydrophobicity changed over time. It has been shown that low molecular weight PDMS chains migrate to the surface, which quickly renders an altered hydrophilic surface into a hydrophobic one [49]. Static contact angle measurements were performed using a Drop Shape Analyzer (DSA30) from Krüss. An automated drop dispenser and deposition system was used to perform the measurements. A $2 \mu \mathrm{L}$ drop of deionized (DI) water was dropped on the material surface and the static contact angle was then determined by the computer software. A minimum of four trials were performed on different parts of the sample surface and two samples from each formulation were tested, giving eight pairs of contact angles for each material. The reported values of static contact angle are an average and standard deviation of the measurements.

Solvent swelling and gel permeation chromatography (GPC) experiments were used to evaluate the crosslinking density and molecular weight of the non-bound extracts, respectively. Solvent swelling and GPC were performed using toluene and chloroform, respectively, which are good solvents for PDMS [6,50-52]. For GPC, $5.5 \pm 5 \mathrm{~g}$ of each sample was swollen in $20 \mathrm{~g}$ of chloroform for $24 \mathrm{~h}$ at $25^{\circ} \mathrm{C}$. After swelling, the excess solvent that was not absorbed by the polymer was filtered using a $0.22 \mu \mathrm{m}$ PTFE filter and then analyzed using an Agilent Infinity II instrument, with a Shodex (K-805L) column, Wyatt Technology detectors, DAWN multi-angle light scattering (MALS, $25{ }^{\circ} \mathrm{C}$ ), and Optilab refractive index (RI, $30^{\circ} \mathrm{C}$ ). The instrument used $75 \mu \mathrm{L}$ of each sample per experiment and ran the material through the column at a rate of $1.0 \mathrm{~mL} / \mathrm{min}$. Data was analyzed using Astra software. Values for the number average molar mass, $\mathrm{M}_{\mathrm{n}}$, weight average molar mass, $\mathrm{M}_{\mathrm{W}}$, and polydispersity, $\mathrm{\Xi}$, were obtained using the Debye model for light scattering, and a refractive index increment $\mathrm{dn} / \mathrm{dc}=-0.0646$. For solvent swelling, Sylgard 184 and its modifications were swollen to equilibrium in toluene for $24 \mathrm{~h}$ at $25^{\circ} \mathrm{C}$ [6]. Additional experiments were run to ensure swelling equilibrium would be attained. Control samples were swollen in toluene for 1, 2,3,6, and 7 days and subsequently vacuum-dried. All the samples had the same relative swollen mass and relative dried mass, thus confirming that swelling equilibrium is reached after one day. After being swollen, the samples were gently patted dry to remove residual toluene before recording the swollen mass. The samples were then dried at $25^{\circ} \mathrm{C}$ for $96 \mathrm{~h}$ under vacuum.

Percent swelling from the solvent is reported as the difference between the fully swollen mass and initial mass. Percent loss from the solvent is reported as the difference between the initial mass and the vacuum dried mass. The network swelling is reported as the difference between the fully swollen mass and vacuum dried mass. Each sample was run in triplicate and standard deviation is reported as the error. Sample dimensions were $11.1 \mathrm{~mm}$ in diameter and $0.98 \pm 0.1 \mathrm{~mm}$ in thickness.

The polymer volume fraction $\varphi_{p}$ was determined using the respective partial volumes of the polymer $V_{p}$ and solvent $V_{s}$. Because these values are not easily measured, the densities of polymer $\rho_{p}$ and solvent $\rho_{s}$ were used along with the network swelling, $S$, to obtain the volume fraction, which is shown as Equation (1). This was used to evaluate 
the Flory-Huggins polymer-solvent interaction parameter $\chi$ between PDMS and toluene, where many equations have been developed to describe the interaction parameter from theory and experimental methods [52-57]. Searching through the literature regarding swelling PDMS with toluene, the equation that best describes the systems in this study is a finite Taylor series as a function of the polymer volume fraction, with values shown in Equation (2) [52].

$$
\begin{gathered}
\varphi_{p}=\frac{V_{p}}{V_{p}+V_{s}}=\left(1+S \frac{\rho_{p}}{\rho_{s}}\right)^{-1} \\
\chi=\chi_{0}+\chi_{1} \varphi_{p}+\chi_{2} \varphi_{p}{ }^{2}=0.459+0.134 \varphi_{p}+0.590 \varphi_{p}{ }^{2}
\end{gathered}
$$

Using the interaction parameter along with the polymer volume fraction and molar volume of the solvent $v_{m, s}$ the average molecular weight of the polymer between crosslinks $M_{c}$ can be evaluated using a modified version of the Flory-Rehner equation. The standard Flory-Rehner equation is derived from thermodynamic interactions and treats the swollen polymer as a perfect network, where the numerator and denominator correspond to the elastic and mixing contributions, respectively [52,58-61]. Groups working with both theoretical and experimental methods regarding polymer swelling behavior have shown that a phantom network models a swollen polymer with better precision and as such is used in this study as Equation (3) [52,58]. The same Flory-Rehner equation can also relate the effective number of chains in the network $v_{e}$ to the average molecular weight of the polymer between crosslinks and Avogadro's number $N_{A}$, shown as Equation (4). Rearranging the terms in Equation (4) produces the specific crosslink density $\mathfrak{p}_{x}$ of the polymer, shown as Equation (5), which describes the moles of crosslinks per mass of polymer.

$$
\begin{gathered}
M_{c}=\frac{-\frac{1}{2} v_{m, s} \rho_{p} \varphi_{p}{ }^{\frac{1}{3}}}{\ln \left(1-\varphi_{p}\right)+\varphi_{p}+\chi \varphi_{p}{ }^{2}} \\
v_{e}=\frac{\rho_{p} N_{A}}{M_{c}} \\
\frac{v_{e}}{\rho_{p} N_{A}}=\frac{1}{M_{c}}=\mathfrak{p}_{x}
\end{gathered}
$$

Mass spectrometry was performed on the headspace of each sealed canister using a Finnigan MAT 271 magnetic-sector mass spectrometer. In addition to the standard Faraday-cup detector, this closed-source, electron-ionization (EI) gas mass spectrometer is equipped with a secondary electron multiplier for detection of trace species. The two detectors were calibrated against standards for several permanent gases. For other gases and vapors, estimates were made from sensitivities based on the electric dipole polarizabilities of molecules, relative to those of the calibration gases [62]. Species were identified by comparison of the measured spectra against the National Institute of Standards and Technology (NIST) electron ionization catalog and the EI fragmentation patterns were used to subtract the contributions of ions of higher-mass molecules from lower-mass peaks. Raw data was in the form of parts per million (ppm) and was converted to moles using the ideal gas law and the measured pressure of the canisters.

\subsection{Mechanical Characterization Techniques}

Shore A Hardness (ShA) testing was performed on a benchtop HPE II Zwick Roell Shore A hardness tester using discs with a diameter of $29 \mathrm{~mm}$ and a thickness between 10 and $13 \mathrm{~mm}$, because samples with a thickness greater than $6 \mathrm{~mm}$ reduce the error associated with the test [13]. Values were taken at equilibrium when the hardness reading had stopped changing. Hardness values were averaged using three samples that were each tested in at least three different locations. Standard deviation is reported as the error.

Tensile strength was measured using an ADMET eXpert 7601 testing system. All samples were cut into dumbbell shapes, referred to as dogbones, using a type-A specimen 
die following ASTM D412 standards. The samples were loaded into the uniaxial grips and then pulled to reach a break point at the speed of $3.84 \mathrm{~mm} / \mathrm{sec}$. Three trials were performed for each sample and the engineering stress, strain, and Young's modulus are reported as averages and corresponding standard deviations.

\subsection{Thermal Characterization Techniques}

Thermogravimetric analysis (TGA) experiments were conducted to evaluate the thermal stability of the samples. TGA was performed using a TA Instrument TGA 550, Discovery Series. Samples weighing $10 \mathrm{mg} \pm 1 \mathrm{mg}$ were heated at a temperature ramping of $5{ }^{\circ} \mathrm{C} / \mathrm{min}$ to $750{ }^{\circ} \mathrm{C}$ under nitrogen passing through the furnace at $40 \mathrm{~mL} / \mathrm{min}$. The onset of thermal degradation $T_{d 5 \%}$ is a measure of thermal stability and applicability, which is determined from the temperature at which the residual mass is $95 \%$ of the total. The temperature of thermal decomposition is that temperature at which the derivative graph (DTGA) is a maximum. Differential Scanning Calorimetry (DSC) experiments were conducted to determine the glass transition temperature $T_{g}$, along with any phase transitions. DSC experiments were performed using a TA Instrument, DSC Q20a, Q Series. The samples, weighing between 5 and $10 \mathrm{mg}$, were cooled down at $10^{\circ} \mathrm{C} / \mathrm{min}$ to $-150{ }^{\circ} \mathrm{C}$, ramped at $5{ }^{\circ} \mathrm{C} / \mathrm{min}$ to $-100^{\circ} \mathrm{C}$, and then ramped at $10{ }^{\circ} \mathrm{C} / \mathrm{min}$ to $30^{\circ} \mathrm{C}$. The reported glass transition temperatures are those found along the heating curve. Coefficient of linear thermal expansion (CTE) experiments were conducted using the dilatometer TA Instrument DIL 802. Cylindrical samples measuring approximately $19.00 \mathrm{~mm}$ in length and $4.5 \mathrm{~mm}$ in diameter were placed next to a fused silica standard and heated under nitrogen at a rate of $5{ }^{\circ} \mathrm{C} / \mathrm{min}$ until the furnace reached $150{ }^{\circ} \mathrm{C}$. The $\mathrm{CTE}$ value $\alpha$, evaluated using Equation (6), was provided by the instrument's software based on the change in length $\Delta L$, change in temperature $\Delta T$, and original length $L_{0}$. Average values and standard deviations are reported from CTE values after they reached a stable number, typically after the sample reached above $40{ }^{\circ} \mathrm{C}$.

$$
\alpha=\frac{1}{L_{0}} \frac{\Delta L}{\Delta T}
$$

\section{Results and Discussion}

\subsection{Material Properties of Pristine Samples}

Rheology performed on the four formulations (Control, 0pt2, 1pt1, and 1pt2) shows that the gel point, which is when the polymer forms a 3D network and can be used as a comparison for curing time, decreased significantly from the Control to any of the formulations with the Ashby-Karstedt catalyst. The reduction in the time for the gel point to appear was even more significant with samples containing TDS. The rheology results, shown in Figure 1, demonstrate that a small addition to the formulation can speed up the curing of the thermoset elastomer. Compared to the unmodified Control, the Opt2, 1pt1, and 1pt2 formulations had a reduction in gel point time by $86 \%, 94 \%$, and $98 \%$, respectively. From this, it is inferred that a greater amount of Pt and vinyl groups within the Ashby-Karstedt catalyst contribute towards the crosslinking of the prepolymer and resin. This has also been seen when the standard 10:1 ratio of base to hardener is lowered so that there is more platinum that can react with the prepolymer, which leads to a faster curing time $[63,64]$. Studies that demonstrate this fact also demonstrate that Sylgard 184 prepared with the lowered ratio comes with varying mechanical properties. Additionally, from the rheology, it can be inferred that the TDS acts as a bridge between separately formed PDMS chains that would have otherwise have either not joined the network or taken much longer to do so. Thus, incorporating both the Ashby-Karstedt catalyst and TDS allows for more reaction sites and vinyl groups to participate in the crosslinking reaction and make a more connected network. 


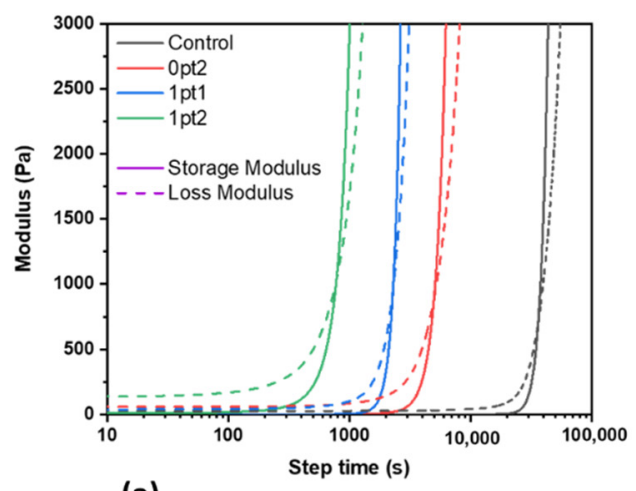

(a)

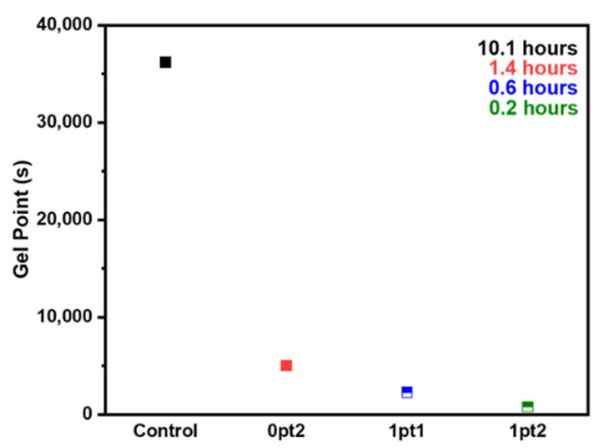

(b)

Figure 1. Rheology of the four formulations: (a) Storage and loss moduli, and (b) Gel point.

The FTIR-ATR spectra for Sylgard 184 is shown in Appendix A as Figure A1 along with five IR peak assignments. Comparing the FTIR spectra for all four formulations reveals distinct regions in similar locations with similar intensities. Thus, the modified formulations do not appear to differ from the Control with respect to chemical functional groups. GPC experiments, which evaluated the molecular weights and distributions of the extractable material in the formulations, showed three peaks for the samples that occurred around two, four, and ten minutes, which correspond to weights of $10^{7}, 10^{6}$, and $10^{3} \mathrm{~g} / \mathrm{mol}$, respectively. All the formulations exhibited these peaks, and the cumulative molar mass distributions for the samples, shown in Appendix A as Figure A2, exhibited similar results for each formulation.

With regards to surface characteristics, Sylgard 184 is naturally hydrophobic due to the methyl end groups on the polymer chain, however it can easily be chemically and physically altered to exhibit other surface characteristics [65]. The Control samples demonstrated a static contact angle with water of $110^{\circ} \pm 9^{\circ}$, which agrees with the literature values reporting measurements of $109^{\circ}$. Measured static contact angles for the modifications are $110^{\circ} \pm 11^{\circ}$ for $0 \mathrm{pt} 2,110^{\circ} \pm 4^{\circ}$ for $1 \mathrm{pt} 1$, and $114^{\circ} \pm 13^{\circ}$ for $1 \mathrm{pt} 2$, thus showing that hydrophobicity is invariant across the formulations.

Swelling experiments on the pristine specimen showed that while all the samples absorbed enough toluene to nearly double their mass, the Control formulation clearly absorbed the most solvent. Indeed, the Control formulation absorbed enough solvent to increase its mass by over $125 \%$, while the modified samples were under $100 \%$. Mass losses after drying were all similar across the samples, measuring at around $4 \%$. Comparisons of swelling between samples are shown in Figure 2a. The measured density of the samples averaged to $0.98 \mathrm{~g} / \mathrm{cm}^{3}$ and is used throughout this study. While the manufacturer reports a density of $1.03 \mathrm{~g} / \mathrm{cm}^{3}$, others such as Olima have reported $1.18 \mathrm{~g} / \mathrm{cm}^{3}$ [3]. Equation (5) provides the specific crosslink densities of the pristine samples, which are shown in Figure $2 \mathrm{~b}$. A decrease in swelling corresponds to an increase in crosslink density; thus, Figure $2 \mathrm{a}, \mathrm{b}$ both describe a similar phenomenon, where the modified samples have a greater specific crosslink density than the Control.

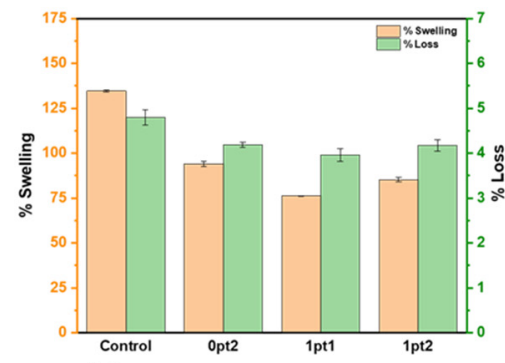

(a)

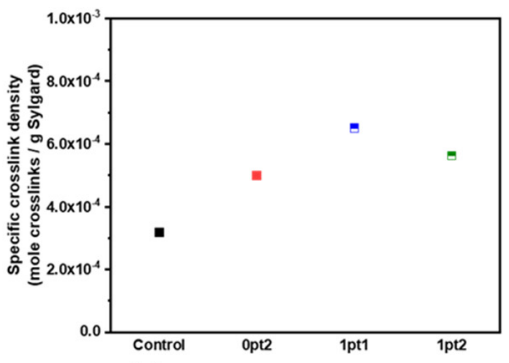

(b)

Figure 2. Solvent swelling experiments of pristine samples in toluene: (a) Swelling and loss percent for the formulations and (b) Specific crosslinking density $\mathfrak{p}_{x}$ for the formulations. 
The mechanical data shows the first recognizable distinction between the four formulations; the modified samples became harder and less flexible on a qualitative basis compared to the Control. Tension tests performed on the dogbone samples confirmed this quantitatively. The results of the tension and hardness tests, shown in Figure 3, demonstrate that all the modified samples become stiffer and less flexible by measure of maximum elongation and stress, and Young's modulus. Hardness measurements, by way of Shore A Hardness durometry, also quantitatively prove that the modified pristine samples are more resistant to indentation than the Control. These results correlate with Figure 2, where an increase in the specific crosslink density is associated with an increase in hardness and Young's modulus.

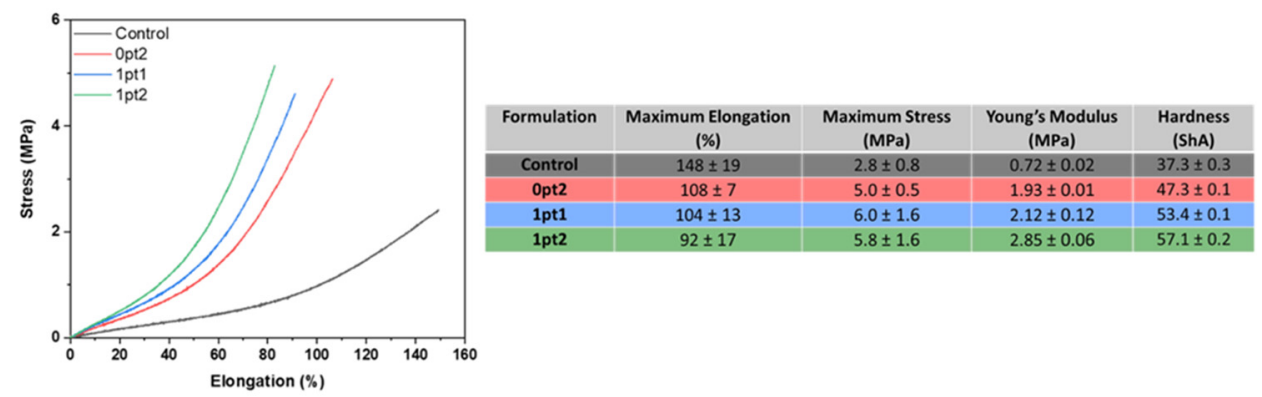

Figure 3. Mechanical properties of pristine samples.

All four formulations exhibit thermal degradation at similar temperatures, as observed in the TGA and DTGA curves in Figure 4. Figure $4 \mathrm{~b}$ shows all the DTGA curves, magnified four times so that the peaks are more readily observed. Differences in thermal stability between the modified and unmodified Sylgard 184 samples were compared using the onset of thermal degradation $T_{d 5 \%}$, which is the temperature at which the materials lose $5 \%$ of their initial mass. While the Control sample exhibited an onset degradation temperature of $370{ }^{\circ} \mathrm{C}$, the $T_{d 5 \%}$ for all the modified samples were similar, with values of $355{ }^{\circ} \mathrm{C}$ for $0 \mathrm{pt} 2,352{ }^{\circ} \mathrm{C}$ for $1 \mathrm{pt} 1$, and $355^{\circ} \mathrm{C}$ for $1 \mathrm{pt} 2-\mathrm{a} 15^{\circ} \mathrm{C}$ decrease. Additionally, the modified formulations had similar thermal degradation mechanisms, where residual masses were comparable (Figure 4a) and thermal decomposition peaks were located at the same temperatures (Figure $4 \mathrm{~b}$ ), while the Control sample sharply deviated after the first thermal degradation mechanism. Furthermore, the Control sample had a $30 \mathrm{wt} \%$ lower residual mass than the modified formulations, indicating that more volatile products were formed due to thermal decomposition. The high residual mass exhibited in Figure 4a has also been observed in the literature for Sylgard 184 and some silicone polymers [3,66-68]. The greatest difference in the degradation profiles was in the quality of the peaks. In the DTGA curves for the modified samples, three peaks are observed, with the greatest relative peak being the first one, which occurs around $360{ }^{\circ} \mathrm{C}$ and is comparable to literature values for PDMS decomposition [36,37,69]. Additionally, all three peaks occur in similar temperature regions for the modified samples. This is in contrast to the Control, where the second peak is so pronounced that it obscures the others in the pristine sample. The decomposition peaks from the DTGA curves correspond to approximately $360{ }^{\circ} \mathrm{C}, 470{ }^{\circ} \mathrm{C}$, and $650{ }^{\circ} \mathrm{C}$ in nitrogen. These have been observed before and have been attributed to the depolymerization process of the chain backbone $[3,41,70]$. Figure 4 demonstrates that the pristine Control samples are initially more thermally stable, and the chain backbone can withstand greater thermal excitations than the modified samples; however, once the depolymerization process begins to occur, the Control samples rapidly decompose and form volatile products, while the modified formulations decompose less readily. 


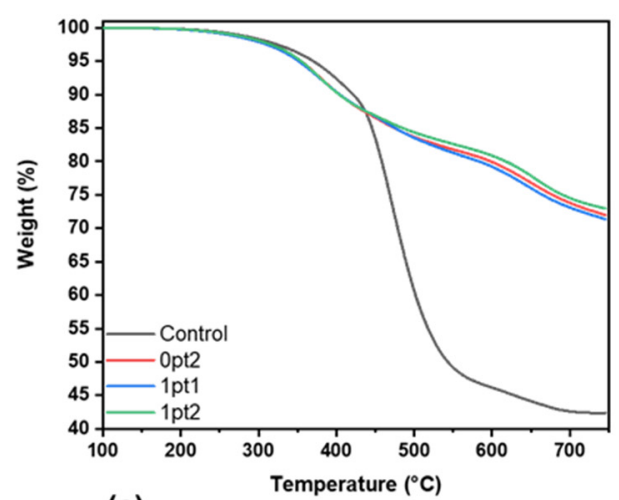

(a)

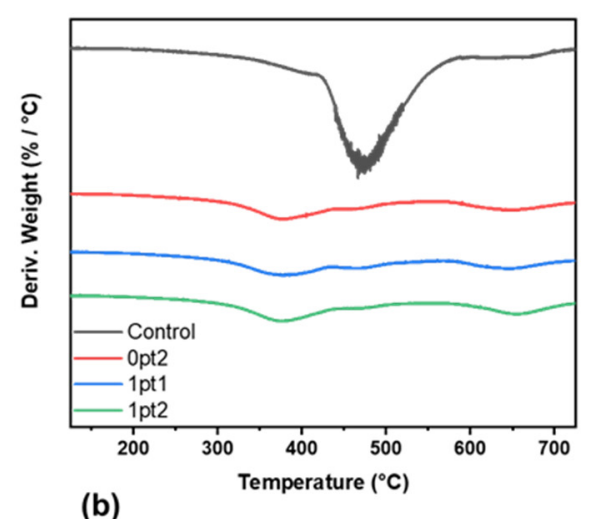

(b)

Figure 4. Thermal stability of pristine samples: (a) TGA curves and (b) DTGA curves magnified.

CTE values were $266 \mathrm{ppm} \mathrm{K}^{-1}$ for the Control, $250 \mathrm{ppm} \mathrm{K}^{-1}$ for $0 \mathrm{pt} 2,203 \mathrm{ppm} \mathrm{K}^{-1}$ for $1 \mathrm{pt} 1$, and $207 \mathrm{ppm} \mathrm{K}^{-1}$ for $1 \mathrm{pt} 2$. Along with the original manufacturer of Sylgard 184 claiming that it has a coefficient of linear thermal expansion of $340 \mathrm{ppm} \mathrm{K}^{-1}$ [8], Liu et al. reports 300 ppm K ${ }^{-1}$ [71], Müller et al. reports $310 \mathrm{ppm} \mathrm{K}^{-1}$ [72], and Kong et al. reports $362 \mathrm{ppm} \mathrm{K}{ }^{-1}$ [73]. The measured CTE values show an improved performance with the modified samples compared to the Control for applications using Sylgard 184, such as micromechanical devices and optical instruments. This is because the polymer is frequently in contact with metals or materials that conduct heat and exhibit low thermal expansion coefficients. Equipment and tools such as these frequently fail due to thermal expansion mismatch, which is why methods that reduce the thermal expansion coefficient are thought to improve performance. The range of CTE values measured for the four formulations and found from the literature demonstrates that while the CTE of Sylgard 184 is significantly higher than most polymers, metals, and other materials, there is a large variability in this property, likely due to fluctuations in different batches.

Glass transition temperatures for all the formulations were similarly at $-120^{\circ} \mathrm{C}$. No crystallization or melting peaks were observed in any heating or cooling cycles, even when the range was extended from $-150^{\circ} \mathrm{C}$ to $200^{\circ} \mathrm{C}$. This agrees with previous results where Sylgard 184 has a $T_{g}$ around $-125^{\circ} \mathrm{C}$ and exhibits no crystallization peaks, making the material a fully amorphous polymer [3].

\subsection{Mechanisms for Aging under Nitrogen}

The Control and 0pt2 samples underwent thermal accelerated aging under a nitrogen atmosphere. Swelling data for the aged Control and 0pt2 samples are shown in Figure 5a,b, respectively. An immediate observation from Figure 5 is that both formulations undergo a post-curing reaction, where the swelling at room and elevated temperatures indicates that the crosslink density increases. A second observation is that after two months of thermal accelerated aging, the swelling of both the Control and 0pt2 samples reaches a plateau, revealing that the majority of the hydrosilylation reaction has run to completion. The third observation, which highlights the difference between the Control and 0pt2 samples, is that the 0pt2 samples experience a lower overall change in swelling than the Control, which occurs more rapidly. A final observation is from the samples aged in air at $90^{\circ} \mathrm{C}$, which are colored yellow and offset in Figure 5 at $92{ }^{\circ} \mathrm{C}$, solely for legibility. Notice that the samples aged in air at $90^{\circ} \mathrm{C}$ exhibit similar swelling behavior to those samples aged in nitrogen at $90^{\circ} \mathrm{C}$. 


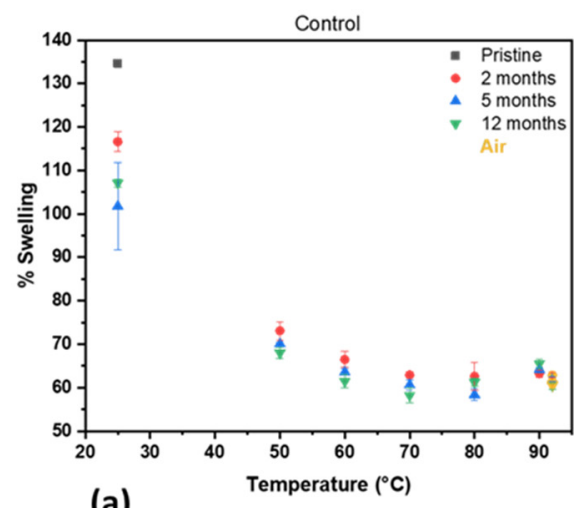

(a)

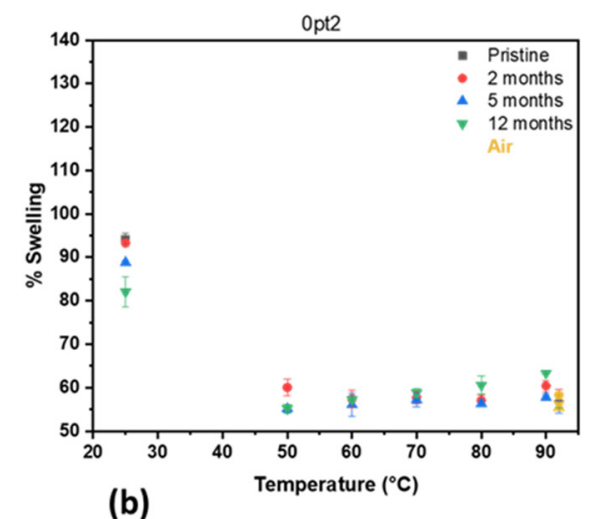

(b)

Figure 5. Swelling of thermally aged samples: (a) Control and (b) 0pt2.

The hydrosilylation reaction responsible for the curing of Sylgard 184 creates crosslinks but does not generate volatile products. Analysis of the headspace of the sealed canisters via mass spectrometry allows for an evaluation of volatile products and can assist in proposing mechanisms responsible for the reactions. The most common evolved products were hydrogen, methane, and ethane, with the former two making up the vast majority of volatiles detected. These can be produced from a proposed reaction mechanism involving water interacting with $\mathrm{Si}-\mathrm{H}$ groups; although the hydrosilylation reaction is an addition reaction between $\mathrm{Si}-\mathrm{H}$ and vinyl groups in the presence of a catalyst, notably $\mathrm{Pt}$, water can also attack $\mathrm{Si}-\mathrm{H}$ to form $\mathrm{Si}-\mathrm{OH}$ in the presence of the same catalyst $[17,34]$. Additionally, siloxanols can be created from the hydrolysis of PDMS, where a water molecule attacks a siloxane chain, resulting in a chain scission and two hydroxyl-terminated chains [74-76]. If a siloxanol encounters a silane, a new crosslink will form between the two moieties and $\mathrm{H}_{2}$ gas will be produced. If, however, a siloxanol encounters a $\mathrm{Si}-\mathrm{CH}_{3}$ group instead, a new crosslink will form between the two moieties and $\mathrm{CH}_{4}$ gas will be produced $[77,78]$. Ethane is produced in a similar manner, except with a $\mathrm{Si}-\mathrm{C}_{2} \mathrm{H}_{5}$ group encountering a siloxanol.

The cumulative amounts of hydrogen and methane in the Control and 0pt2 samples are shown in Figure 6. Furthermore, samples that were aged at $90^{\circ} \mathrm{C}$ in air are included as before: yellow and offset in Figure 6 to $92{ }^{\circ} \mathrm{C}$, solely for legibility. Two initial observations stand out, which are that as time progresses and temperature increases, the cumulative amount of volatiles becomes greater. Additional interesting observations can be made when comparing volatile product generation between the two formulations. One would be that there is more hydrogen generation for the Control than 0pt2 samples. The other would be the case for methane generation, where $0 \mathrm{pt} 2$ generated much more methane than Control samples.

The proposed mechanism, which depends on trace water, should be able to be indirectly observed via $\mathrm{Si}-\mathrm{OH}$ bonds. Based on FTIR data, there are peaks around $845 \mathrm{~cm}^{-1}$ and $865 \mathrm{~cm}^{-1}$ (shown in the Appendix A as Figure A3), which correspond to Si-O stretching in $\mathrm{Si}-\mathrm{OH}$ [65]. Additionally, mass spectrometry revealed small amounts of trace water (in ppm levels) in the headspace. Although the FTIR data was not quantitatively analyzed, reviewing the spectra and mass spectrometry of the samples lends credence towards this proposed mechanism. The addition of the $2 \% \mathrm{Pt}$ Ashby-Karstedt catalyst, which introduces more vinyl groups and thus promotes crosslinking, leaves fewer available $\mathrm{Si}-\mathrm{H}$ groups for $\mathrm{H}_{2}$ generation. Thus, the 0pt2 samples should be expected to generate less $\mathrm{H}_{2}$ gas than the Control samples but generate more $\mathrm{CH}_{4}$. Additionally, observe how the volatile gas production in Figure 6 increases with temperature; greater thermal energy leads to more chain mobility and thus more interactions between siloxanes, silanes, and siloxanols. Thus, the proposed mechanism provides an explanation for the observed data. 


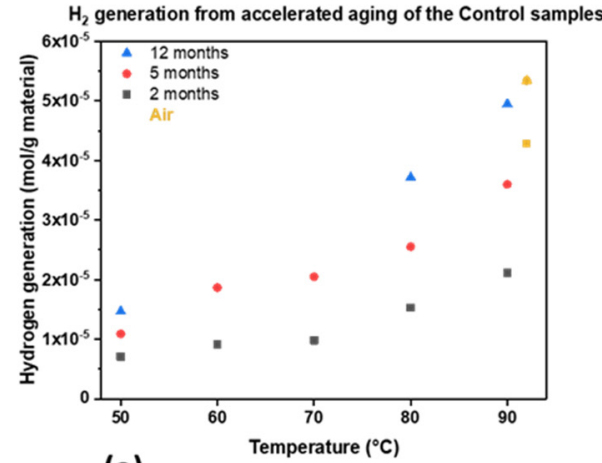

(a)

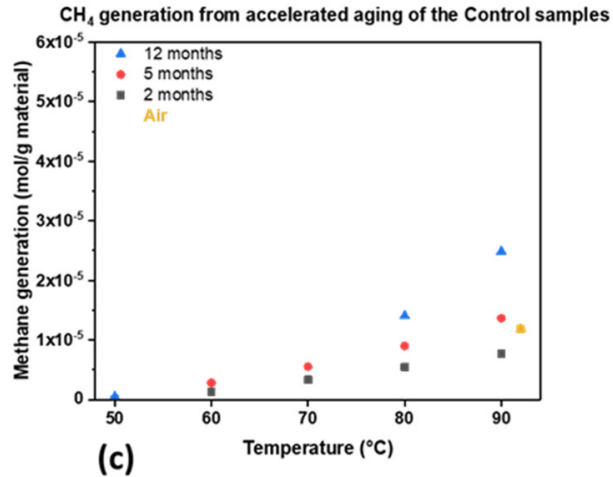

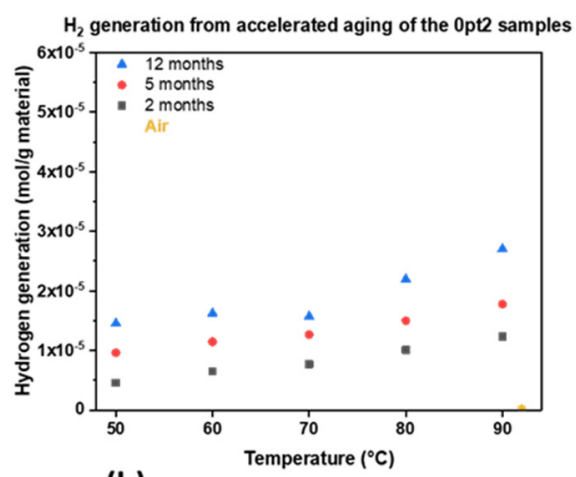

(b)

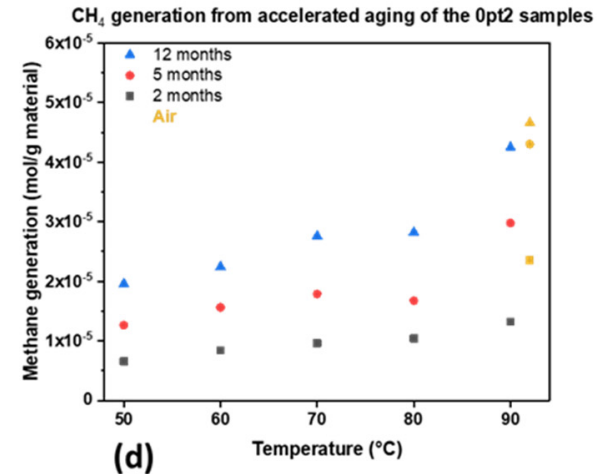

Figure 6. Measuring the volatile products that evolved while undergoing thermal accelerated aging on a per-mass-of-Sylgard basis: (a) hydrogen generation from the Control; (b) hydrogen generation from 0pt2; (c) methane generation from the Control; and (d) methane generation from 0pt2.

It is possible to draw conclusions about the specific crosslink density using Equation (5). Based on the proposed mechanisms, all the crosslinks in the polymer network are assumed to be from the hydrosilylation (cure and post-cure) and trace water-promoted reactions. Treating the specific crosslink density as separable with regards to reactions that generate crosslinks, it can be thought of as the sum of the specific crosslink density due to hydrosilylation $\mathfrak{p}_{x}^{\text {hydrosilylation }}$ and water reactions $\mathfrak{p}_{x}^{\text {radical } / \text { water }}$ as shown in Equation (7). Because the hydrosilylation reaction does not generate volatile gas, each molecule of volatile gas is produced as a result of a crosslink formed from a trace water reaction. Thus, summing the moles of hydrogen, methane, and ethane measured via mass spectrometry yields the amount of crosslinks formed due to trace water. Additionally, Equation (7) can be used to define the fraction of specific crosslink density due to trace water $\eta_{w a t e r}$ as shown in Equation (8).

$$
\begin{gathered}
\mathfrak{p}_{x}=\mathfrak{p}_{x}^{\text {hydrosilylation }}+\mathfrak{p}_{x}^{\text {water }} \\
\eta_{\text {water }}=\frac{\mathfrak{p}_{x}^{\text {water }}}{\mathfrak{p}_{x}^{\text {hydrosilylation }}+\mathfrak{p}_{x}^{\text {water }}}
\end{gathered}
$$

Equation (8) can now be used to observe how changes in the specific crosslink density for the aged formulations (shown in the Appendix A as Figure A4) are due to various reactions. Using the mass spectrometry data along with the swelling data allows for an understanding of crosslinking behavior due to the cure, post-cure, and trace water reactions, which is shown in Figure 7. The specific crosslink densities due to hydrosilylation reactions for Controls and 0pt2 (Figure 7a,b) show that the amount of crosslinks per mass of Sylgard does not change significantly-which mimics the swelling data. Indeed, both the Control and 0pt2 samples seem to level off between $0.7-0.8 \mathrm{mmol}$ of crosslinks due to curing and post-curing per gram of Sylgard. Additionally, 0pt2 samples converge to the plateau at a much earlier time than the Control, whereas after two months the 0pt2 samples do not exhibit any significant change in specific crosslink density. Furthermore, the fraction of 
specific crosslink density due to trace water reactions (Figure 7c,d) increases over time and temperature. Thus, while the post-curing reaction ceases after two months and stops contributing to the specific crosslink density, the trace water reactions continue to promote crosslinking and gas evolution.

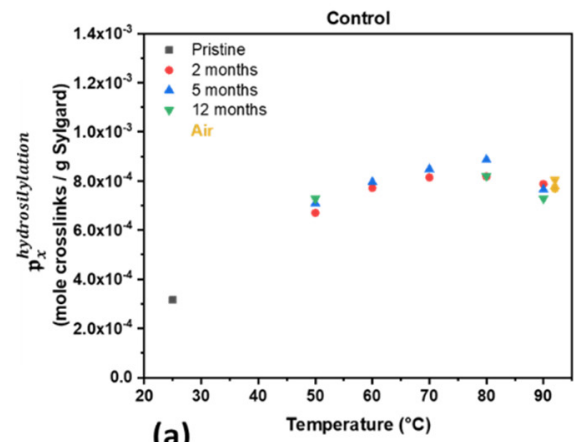

(a)

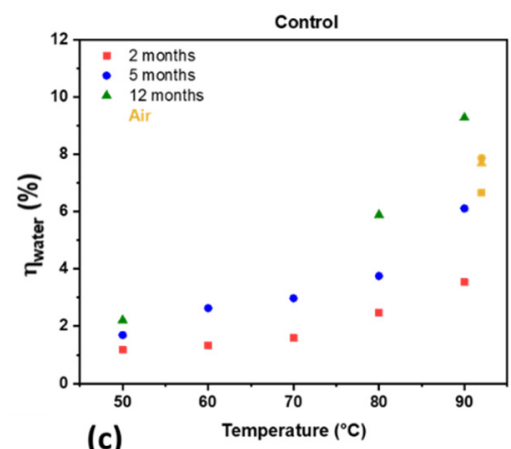

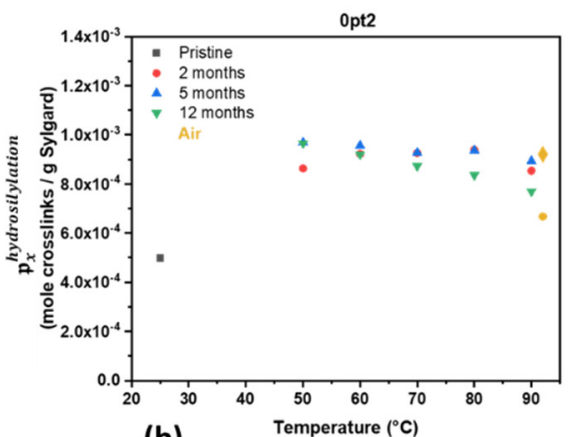

(b)

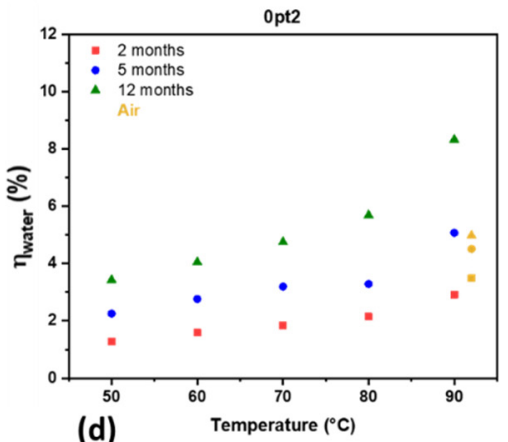

(d)

Figure 7. Specific crosslink density: (a) Crosslinks due to hydrosilylation for Controls; (b) Crosslinks due to hydrosilylation for 0pt2; (c) Water fraction for Controls; and (d) Water fraction for 0pt2.

Traditionally, time-temperature superposition (TTS) is performed in relation to stress, creep, or dynamic loading, but in essence, material properties need to be measured and compared to a reference for the principle to be applicable. Because the aging temperatures used in this study are well below that of any thermal decomposition and well above any thermal phase transition, mass spectrometry can be used according to TTS and a master curve can be created as a function of shift time. The lowest temperature used for mass spectrometry, $50^{\circ} \mathrm{C}$, was the reference temperature $T_{0}$. After two months, the shift factor $a_{T}$ was defined in terms of the moles of gas produced $n$, shown in Equation (9), which allowed for a new axis of shift time $a_{T} t$ to be used, where all the data can be superimposed. For specific degradation or reaction mechanisms, if Arrhenius behavior was followed, the apparent activation energy $E$ can be defined in terms of the universal gas constant $R$, the shift factor, and differences in reciprocal temperatures in Kelvin, as shown in Equation (10). Performing TTS with mass spectrometry data can be validated with these equations if there is a linear relationship between $\ln \left(a_{T} t\right)$ and $\frac{1}{T}$, which is shown as Figure A5.

$$
\begin{gathered}
a_{T}=\frac{n_{\text {species }}(T)}{n_{\text {species }}\left(T_{0}\right)} \\
E=\frac{R \ln \left(a_{T}\right)}{\frac{1}{T_{o}}-\frac{1}{T}}
\end{gathered}
$$

By plotting all the evolved gases (hydrogen, methane, and ethane) for the Control and 0 pt2 samples against shift time, a trend can be observed. Using statistical regression, the superposition data was modeled with a power function. These are shown in Figure 8 along with the coefficient of determination $R^{2}$. Although Figure 6 shows that the Control samples 
generate more hydrogen than $0 \mathrm{pt} 2$, enough methane and ethane were generated by $0 \mathrm{pt} 2$ to have its model appear greater for overall volatile gas production. Power functions were used in the superposition model because there were few volatiles evolved at the beginning of aging but gradually increased as more time went on. The average activation energy for the Control and 0pt2 samples was $38.2 \mathrm{~kJ} / \mathrm{mol}$ and $15.5 \mathrm{~kJ} / \mathrm{mol}$, respectively, which is not surprising given that the shifted time values are much closer together for $0 \mathrm{pt} 2$ than the Control.

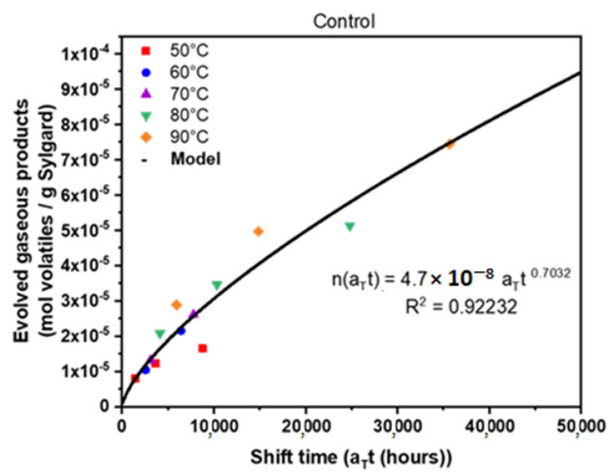

(a)

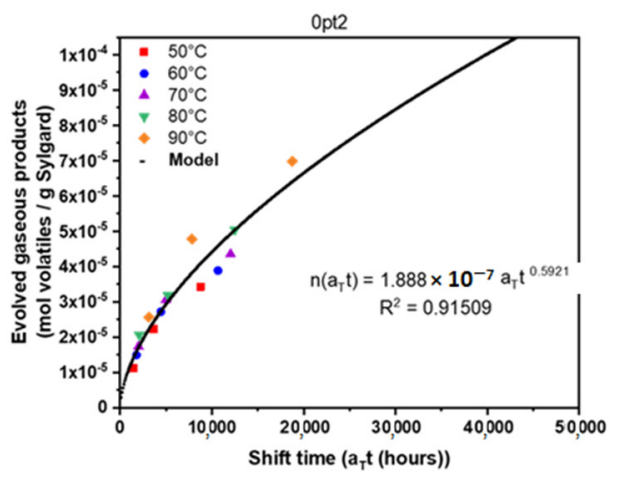

(b)

Figure 8. Time-temperature superposition master curve models of the three major evolved gaseous products: (a) Controls and (b) 0pt2.

Because hydrogen generation is a major known cause of hazards when dealing with siloxanes and silicon-based polymers in general, models were also developed for the Control and 0pt2 samples with regards to hydrogen evolution. Using the same procedure as detailed above for all major volatiles, the power law models were derived. For the Controls, the coefficient and exponent in shift time are $4.22 \times 10^{-8}$ and 0.7257 , respectively. For the 0 pt2, the coefficient and exponent in shift time are $1.2 \times 10^{-7}$ and 0.5391 , respectively. Plots of these models are shown together in the Appendix A as Figure A6. The average apparent activation energy for the Control and 0pt2 samples was $33.4 \mathrm{~kJ} / \mathrm{mol}$ and $14.4 \mathrm{~kJ} / \mathrm{mol}$, respectively.

It is apparent from Figure 6 that the Control samples generated more hydrogen than 0pt2 samples, while 0pt2 samples generated more methane than Control samples. Interestingly, an oxygen-rich environment (air) causes more hydrogen to be produced by the Controls than in nitrogen, while almost no hydrogen is present for two, five, and twelve months of thermal accelerated aging of the 0pt2 samples. Additionally, an oxygenrich environment causes more methane generation in the 0pt2 samples than an inert environment, while methane ceases to generate in an oxygen-rich environment after two months of aging for the Controls. Indeed, an initial amount of methane was produced after two months at $90{ }^{\circ} \mathrm{C}$ in air, but afterwards the cumulative amount barely increases.

Therefore, the presence of oxygen also has an influence on volatile products. It appears that whichever gas species is more prominent (hydrogen or methane), oxygen increases its production while it sequesters the other evolved gas (methane or hydrogen). These observations can be seen when comparing Figure $6 a, d$ and Figure $6 b, c$. These novel data and results suggest that a preference can be chosen for both the formulation of Sylgard 184 and the atmosphere it is stored in, to selectively generate or suppress certain evolved permanent gases.

\subsection{Material Properties of Aged Samples}

Figure 9 shows the four formulations after twelve months of thermal accelerated aging. There is a general trend, where aging at higher temperatures leads to a greater amount of discoloration. This is exhibited in every formulation and throughout the interior of the samples, although the extent of discoloration is more pronounced in the modified specimen. The clear-to-yellow discoloration phenomenon of silicones is known to be 
caused by platinum-complex interactions and does not affect material performance [79-82]. Interestingly, all samples produce an obvious yellowing at $80^{\circ} \mathrm{C}$ if they haven't already been discolored. The greater discoloration of the modified samples can be explained due to the addition of the Asbhy-Karstedt catalyst, which introduces more platinum to complex. Furthermore, the addition of TDS prevents discoloration up to $70{ }^{\circ} \mathrm{C}$ when comparing $1 \mathrm{pt} 1$ and $1 \mathrm{pt} 2$ samples to $0 \mathrm{pt} 2$. The Control samples, which have no additional platinum added, exhibit the least discoloration. Comparing aging in nitrogen versus air, while the 0pt2 samples were all yellow, the samples aged in air were the deepest brown color, and the Control sample aged in air did not experience a yellowing effect at all.

\section{Months of Thermal Accelerated Aging}

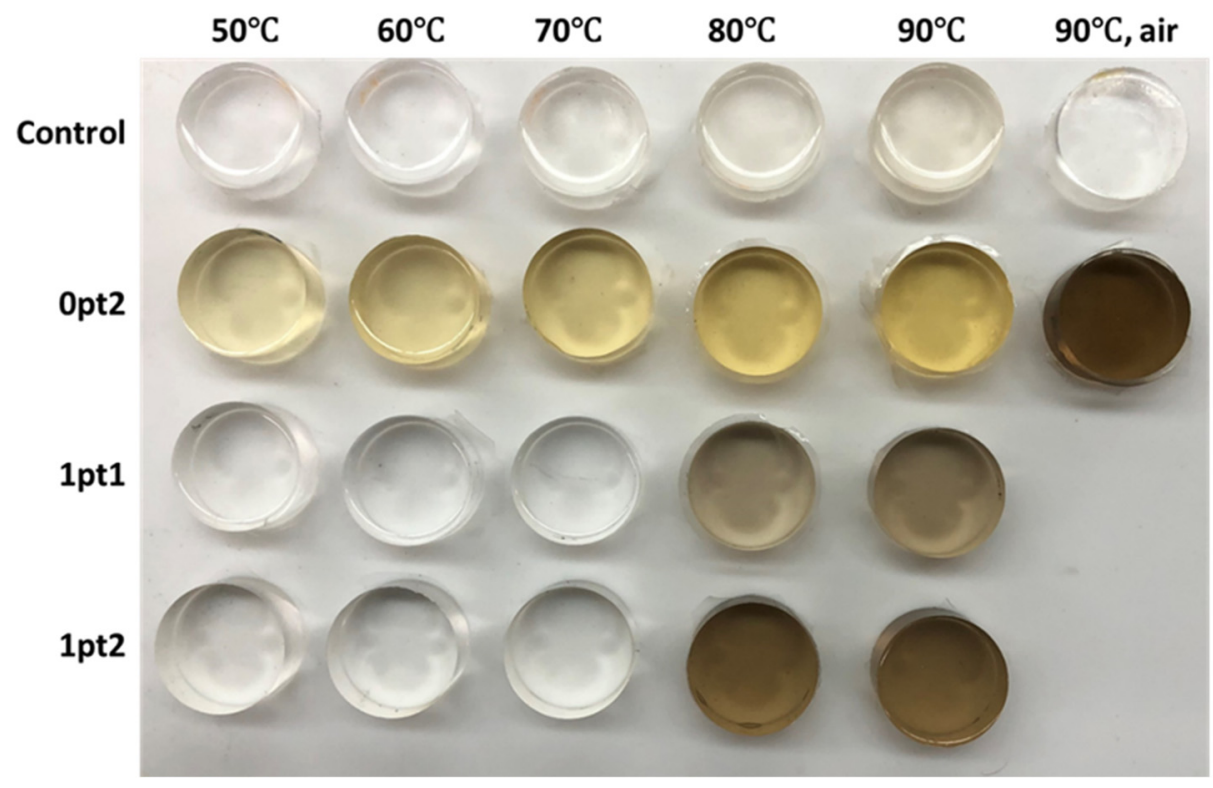

Figure 9. Discoloration of the four formulations after 12 months of thermal accelerated aging.

From a chemical structure perspective, the FTIR data show that the peaks for all formulations make a near perfect superposition when comparing aging time and temperature. Additionally, no new peaks have formed. Thus, any chemical changes within the material are the product of the rearrangement of bonds, due to furthering the hydrosilylation reaction and other crosslinks due to trace water. Over time, all the aged formulations still exhibited contact angles above $90^{\circ}$, thus they continued to demonstrate hydrophobicity. No significant changes to hydrophobicity were observed during the aging process.

The 1pt1 and 1pt2 formulations exhibited a decrease in solvent swelling similar to the others shown in Figure 5, where there was an increase in the specific crosslink density for all the formulations over their aging conditions. It should be noted that during swelling experiments, the mass of the extracts for all the samples changed little from the pristine, exhibiting values around $3.5 \%$. For swelling, there is significantly less change after two months of aging, where considerable overlap occurs between five and twelve months. The final swelling values, taken from samples aged at $90{ }^{\circ} \mathrm{C}$ for 12 months in air, were $60 \%$, $56 \%, 58 \%$, and $56 \%$ for the Control, $0 \mathrm{pt} 2$, $1 \mathrm{pt} 1$, and $1 \mathrm{pt} 2$ samples, respectively. For the same samples, the final specific crosslink densities were $8.7 \times 10^{-4}, 9.6 \times 10^{-4}, 9.3 \times 10^{-4}$, and $1.0 \times 10^{-3}$ mole crosslinks/gram Sylgard for the Control, $0 \mathrm{pt} 2,1 \mathrm{pt} 1$, and $1 \mathrm{pt} 2$ samples, respectively. Evaluating the relative changes for swelling and specific crosslink density demonstrated that the Control formulation experienced a greater overall change compared to the modified samples for both quantities.

Similar trends were observed for mechanical properties. Like the swelling data, there were no statistically significant differences between the samples aged at $90^{\circ} \mathrm{C}$ in nitrogen or air; the atmosphere did not affect the final values of the mechanical properties. Obtaining 
values from the samples aged at $90^{\circ} \mathrm{C}$ for 12 months in air, the final mechanical properties are displayed in Table 2. Similar to swelling behavior, the Control samples exhibited the greatest percent change overall, which can be seen when comparing the values from Table 2 with Figure 3. In general, all the formulations became harder and stiffer over time, along with the materials not being able to be stretched as much as they originally could without breaking. As an example, the Control, $0 \mathrm{pt} 2,1 \mathrm{pt} 1$, and $1 \mathrm{pt} 2$ samples increased in Shore A Hardness after thermal aging by $72 \%, 40 \%, 26 \%$, and $20 \%$, respectively. Thus, final values for maximum elongation decreased, while Shore A Hardness, maximum stress, and Young's modulus increased.

Table 2. Final mechanical properties of the four Sylgard 184 formulations.

\begin{tabular}{ccccc}
\hline Formulation & $\begin{array}{c}\text { Maximum Elongation } \\
(\mathbf{\%})\end{array}$ & $\begin{array}{c}\text { Maximum Stress } \\
\mathbf{( M P a )}\end{array}$ & $\begin{array}{c}\text { Young's Modulus } \\
\text { (MPa) }\end{array}$ & $\begin{array}{c}\text { Shore A Hardness } \\
\text { (ShA) }\end{array}$ \\
\hline Control & $74 \pm 3$ & $10.4 \pm 0.7$ & $5.74 \pm 0.27$ & $64.3 \pm 0.3$ \\
\hline 0pt2 & $65 \pm 5$ & $8.8 \pm 1.4$ & $6.23 \pm 0.32$ & $66.4 \pm 0.5$ \\
\hline 1pt1 & $70 \pm 3$ & $10.8 \pm 1.1$ & $6.86 \pm 0.23$ & $67.3 \pm 0.8$ \\
\hline 1pt2 & $63 \pm 3$ & $9.3 \pm 1.2$ & $6.91 \pm 0.40$ & $68.4 \pm 0.7$ \\
\hline
\end{tabular}

Shore A Hardness values were used for making TTS predictive master curves, which are shown in Figure 10. The reference temperature used in the procedure was $50{ }^{\circ} \mathrm{C}$. Because hardness is generally monotonic and reaches a limit (Figure A7 in the Appendix A), a logistic curve was used to fit the shift time data using Equation (A1). The parameters of each logistic curve are given in Appendix A Table A1. An interesting observation from performing this procedure is that the apparent activation energy at a given temperature is about $20 \%$ more than the activation energy for samples aged at $10{ }^{\circ} \mathrm{C}$ higher. For the highest temperature, $90^{\circ} \mathrm{C}$, the apparent activation energies were $9.0 \mathrm{~kJ} / \mathrm{mol}, 5.0 \mathrm{~kJ} / \mathrm{mol}$, $1.9 \mathrm{~kJ} / \mathrm{mol}$, and $1.4 \mathrm{~kJ} / \mathrm{mol}$ for the Control, $0 \mathrm{pt} 2,1 \mathrm{pt} 1$, and $1 \mathrm{pt} 2$ formulations, respectively. Similar to the mass spectrometry data, a plot to validate using TTS models for hardness data is shown in Figure A8. From the TTS master curve model, aging at an elevated temperature of $50{ }^{\circ} \mathrm{C}$ would take 82 days, 39 days, 38 days, and 35 days for the Control, $0 \mathrm{pt} 2,1 \mathrm{pt} 1$, and $1 \mathrm{pt} 2$ samples, respectively, to reach $95 \%$ of their final hardness values.

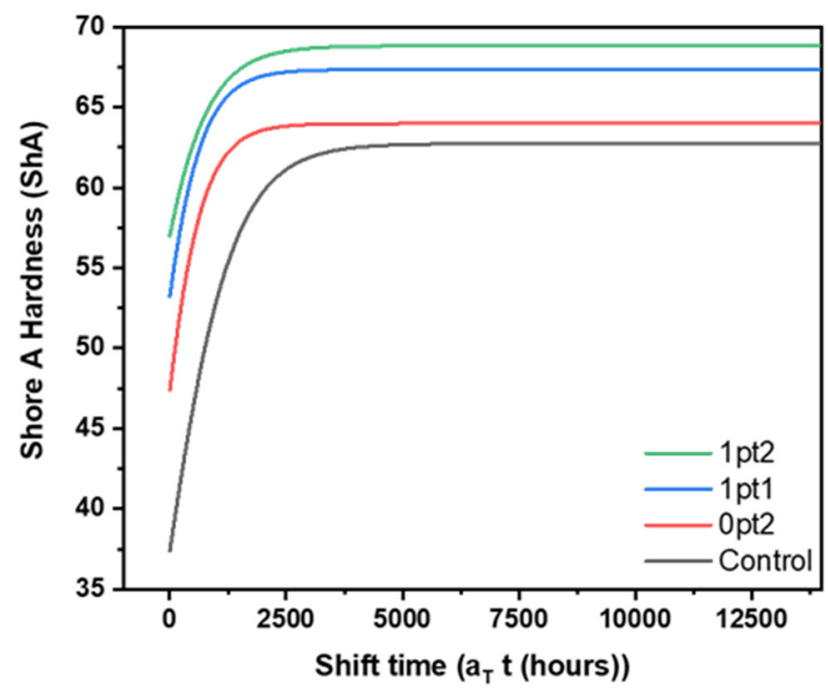

Figure 10. Time-temperature superposition master curve models of Shore A Hardness for the four thermal accelerated aged Sylgard 184 formulations.

The onset of thermal degradation, $\mathrm{Td} 5 \%$, for the formulations changed throughout the aging process. To better visualize trends due to accelerated aging, linear regression 
was performed on the data. This linear regression found the best fit line for $\mathrm{Td} 5 \%$ against aging temperature and aging time, and is displayed for the four formulations in Figure 11. Additionally, the listed slopes in the figure provide insight into how the thermal stability of the formulations will change over their lifespan. From Figure 11, all the modified formulations become more thermally stable for increasing aging temperatures while the Control remains steady. The largest changes came from the TDS-modified samples, which experienced a $10 \%\left(40{ }^{\circ} \mathrm{C}\right)$ increase in thermal stability. Control samples aged in air had similar thermal stability as those aged in nitrogen and the $0 \mathrm{p} 2$ samples aged in air had an increase in thermal stability when compared against those aged in nitrogen.

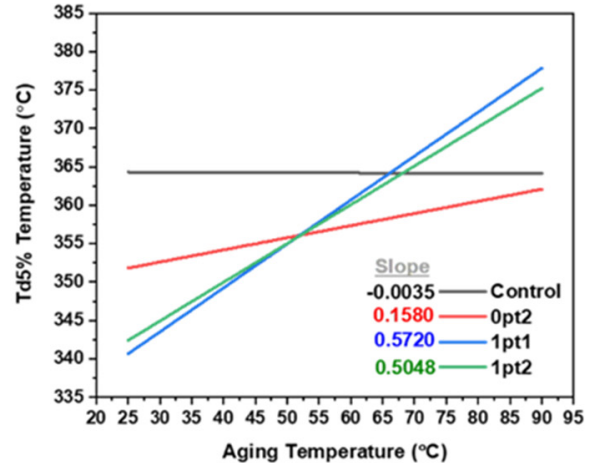

(a)

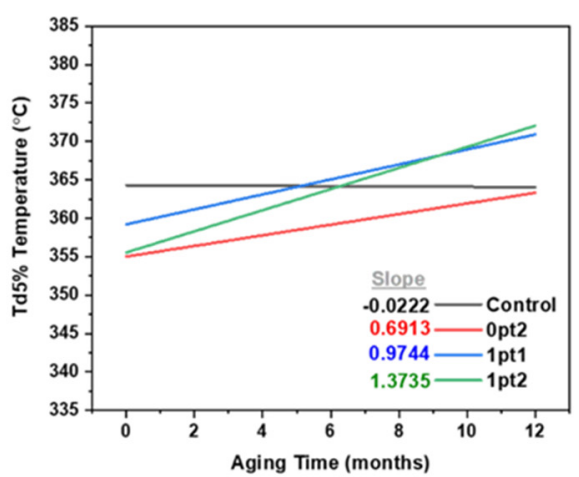

(b)

Figure 11. Linear regression of thermally aged samples (a) as a function of aging temperature and (b) as a function of aging time.

The glass transition temperature for all the formulations remained at $-120^{\circ} \mathrm{C}$, which was expected, as the aging process occurs well above the glass transition. A similar linear regression treatment was performed for the coefficient of thermal expansion of the aged samples, however no clear trend existed. At the end of the 12 months of aging, all the samples fell within a range of $200-260 \mathrm{ppm} \mathrm{K}^{-1}$.

\section{Conclusions}

This work examined how small chemical changes to Sylgard 184 affected its curing behavior at room temperature. Modified formulations were created using small amounts of the Asbhy-Karstedt catalyst (a complex of $2 \% \mathrm{Pt}(0)$ in cyclomethylvinylsiloxanes) and TDS (tetrakis (dimethylsiloxy) silane) — both of which bolster the hydrosilylation reaction that provides curing in the Sylgard framework. The Ashby-Karstedt catalyst introduces more vinyl groups and platinum while TDS introduces more silane reactive groups. It was found that all the modified formulations exhibited a dramatic reduction in working time by over $85 \%$ (less than $1.5 \mathrm{~h}$ ) at room temperature, and that they had a greater degree of crosslinking than the Control.

Thermal accelerated aging was performed on the four formulations (Control, $0 \mathrm{pt}$, $1 \mathrm{pt1}$, and 1pt2) in isothermal conditions at $25{ }^{\circ} \mathrm{C}, 50{ }^{\circ} \mathrm{C}, 60^{\circ} \mathrm{C}, 70{ }^{\circ} \mathrm{C}, 80{ }^{\circ} \mathrm{C}$, and $90^{\circ} \mathrm{C}$ - spanning time periods of two, five, and twelve months. Additionally, the Control and 0 pt2 samples were aged under controlled nitrogen and air atmospheres so that the evolving gases could be probed. Mass spectrometry data showed that hydrogen, methane, and ethane were the major volatile components of Sylgard 184. Two mechanisms were proposed to be responsible for aging. The hydrosilylation reaction is most responsible for the post-cure, and thus changes to solvent swelling and mechanical behavior, while trace water present throughout the polymer network explained the volatile products. The Flory-Rehner equation, along with the solvent swelling and mechanical data, demonstrate that post-curing ceases after two months of thermal aging. Additionally, using shift factors from the time-temperature superposition principle, master curves were developed for volatile evolution and Shore A Hardness, which can be used to predict lifetime material performance. Mechanical tests demonstrated that all the formulations converge to specific 
limiting values, where all the samples became stiffer and harder over time-with the Control exhibiting the greatest change overall. Indeed, the Control, $0 \mathrm{pt} 2,1 \mathrm{pt} 1$, and $1 \mathrm{pt} 2$ samples increased in Shore A Hardness after thermal aging by $72 \%, 40 \%, 26 \%$, and $20 \%$, respectively. Thermal stability tests showed that the modified samples had an increase in their onset of thermal degradation over aging times and that the Control samples did not change significantly. The largest increase in thermal stability was observed in the TDS samples, which had a $10 \%\left(40{ }^{\circ} \mathrm{C}\right)$ increase in thermal stability, from $350{ }^{\circ} \mathrm{C}$ to $390^{\circ} \mathrm{C}$.

Comparing the four formulations from an initial and aging standpoint, it is clear that the modified samples experience less aging. Indeed, the Control samples demonstrated a greater percent change in solvent swelling and every mechanical property examined (Shore A Hardness, maximum elongation, maximum stress, and Young's modulus), thus illustrating that the material properties of the modified samples are more consistent throughout their lifespan. Additionally, because the material properties vary, Sylgard 184 can be altered to fit specific applications. This extends to volatile gas production, where the formulation and aging atmosphere had an effect on which gases evolved, and in varying quantities. In essence, Sylgard 184 can be tailored with small amounts of well-known compounds to optimize material properties and lifetime performance.

Author Contributions: Conceptualization, Z.B. and A.L.; methodology, Z.B.; software, Z.B.; validation, Z.B.; formal analysis, Z.B. and J.Z.; investigation, Z.B., J.Z., D.G. and N.G.; resources, Z.B. and A.L.; data curation, Z.B. and J.Z.; writing-original draft preparation, Z.B.; writing-review and editing, Z.B., J.Z., D.G. and A.L.; visualization, Z.B.; supervision, Z.B. and A.L.; project administration, Z.B. and A.L.; funding acquisition, A.L. All authors have read and agreed to the published version of the manuscript.

Funding: This work was performed under the US Department of Energy's National Nuclear Security Administration contract DE-AC52-06NA25396.

Data Availability Statement: The authors confirm that the data supporting the findings of this study are available in the article.

Acknowledgments: The authors would like to thank Adam Pacheco for his technical support during this project.

Conflicts of Interest: The authors declare no conflict of interest. The funders had no role in the design of the study; in the collection, analysis, or interpretation of data; in the writing of the manuscript; or in the decision to publish the results.

\section{Appendix A}

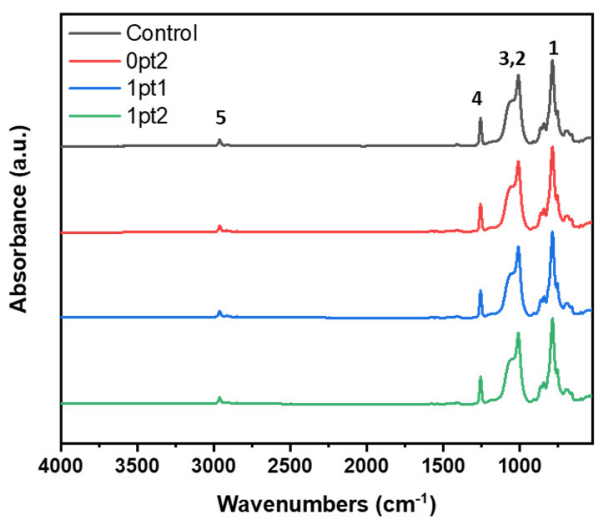

\begin{tabular}{|c|c|c|}
\hline Peak assignment & Wavenumber $\left(\mathrm{cm}^{-1}\right)$ & Vibrational mode \\
\hline 1 & $785-815$ & $\begin{array}{c}-\mathrm{Si}-\mathrm{CH}_{3} \text { stretching } \\
\text { Wagging of }-\mathrm{Si}-\mathrm{CH}_{2}-\mathrm{Si}-\end{array}$ \\
\hline 3 & $1015-1150$ & $\begin{array}{c}\text { Asymmetric }-\mathrm{Si}-\mathrm{O}-\mathrm{Si} \\
\text { stretching }\end{array}$ \\
\hline 4 & $1100-1170$ & $\begin{array}{c}\text { Symmetric }-\mathrm{Si}-\mathrm{CH}_{3} \\
\text { deformation }\end{array}$ \\
\hline 5 & $1245-1270$ & $\begin{array}{c}\text { Asymmetric }-\mathrm{Si}_{-}-\mathrm{CH}_{3} \\
\text { stretching }\end{array}$ \\
\hline
\end{tabular}

Figure A1. FTIR spectra of formulations along with their peak assignments. 


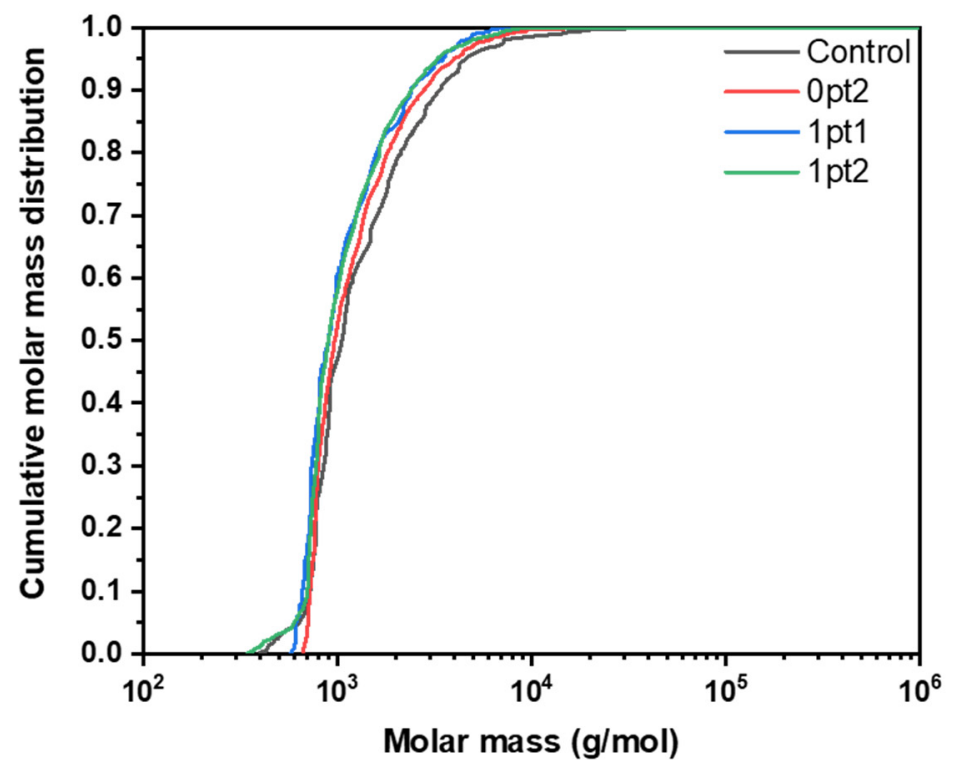

Figure A2. Cumulative molar mass distribution of the extracts from pristine samples.

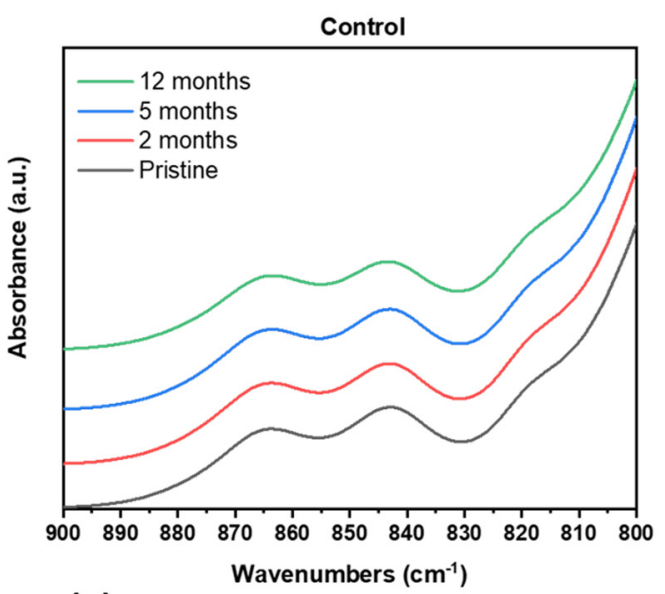

(a)

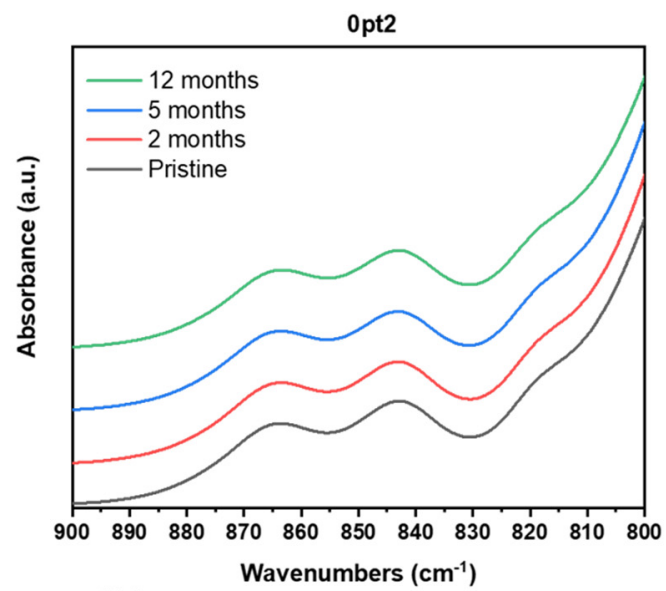

(b)

Figure A3. FTIR absorbance spectra of pristine and $50{ }^{\circ} \mathrm{C}$ aged samples showing peaks at $845 \mathrm{~cm}^{-1}$ and $865 \mathrm{~cm}^{-1}$, which correspond to siloxanol groups ( $\mathrm{Si}-\mathrm{OH})$ : (a) Controls and (b) $0 \mathrm{pt} 2$.

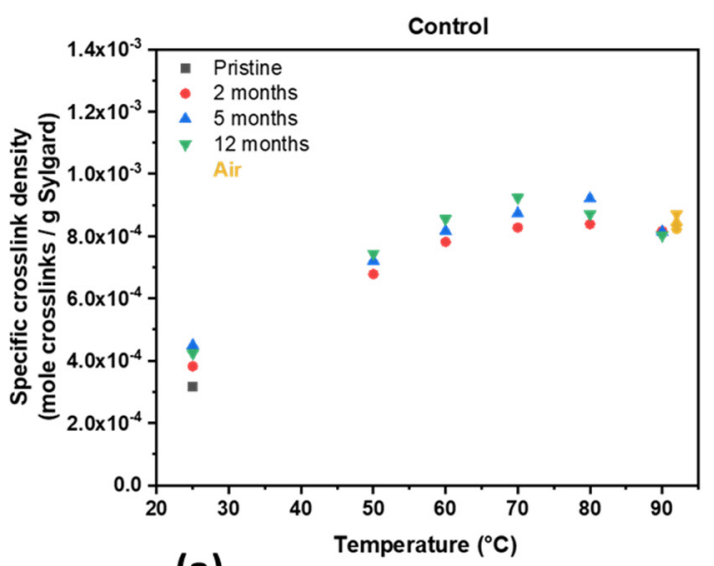

(a)

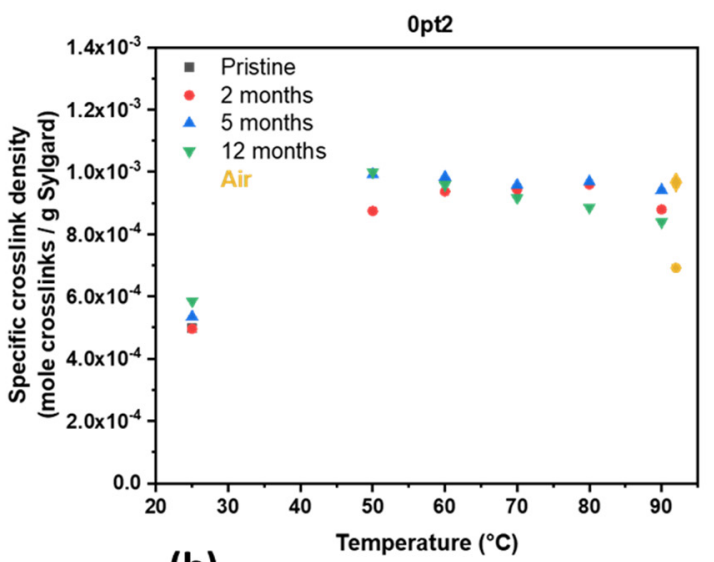

(b)

Figure A4. Cont. 


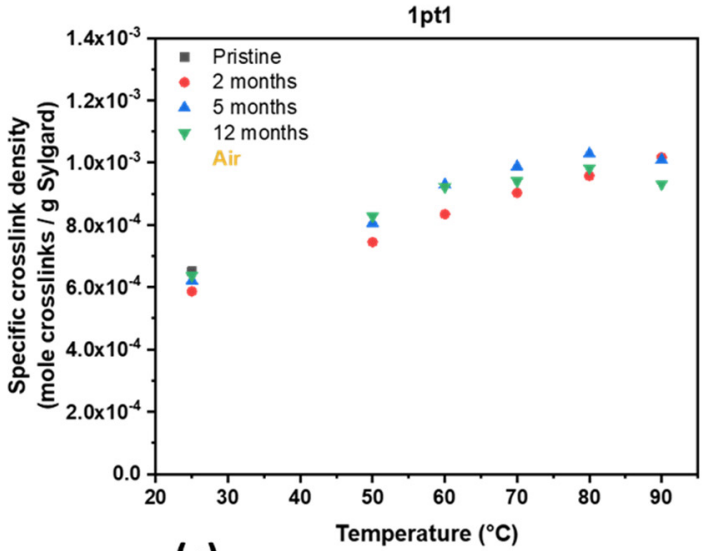

(c)

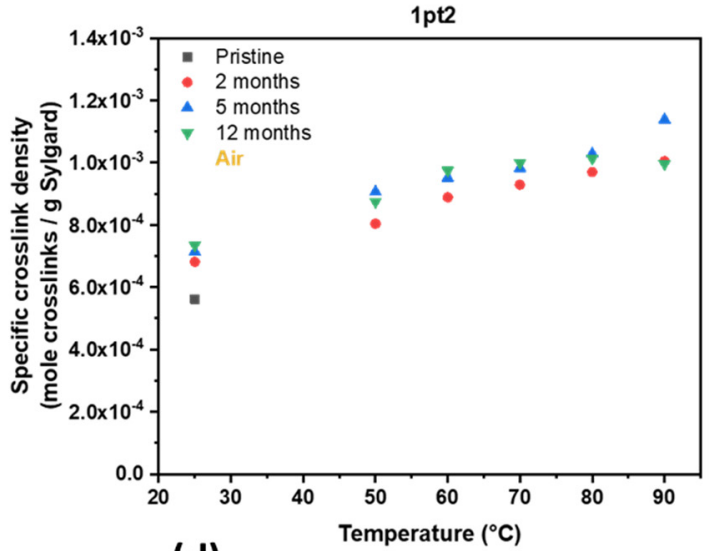

(d)

Figure A4. Specific crosslink densities of thermally aged samples: (a) Controls; (b) 0pt2; (c) 1pt1; and (d) 1pt2.

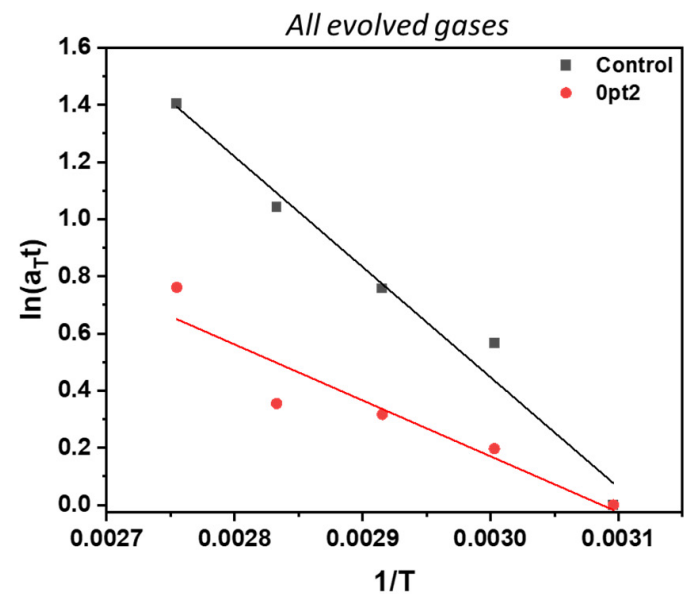

(a)

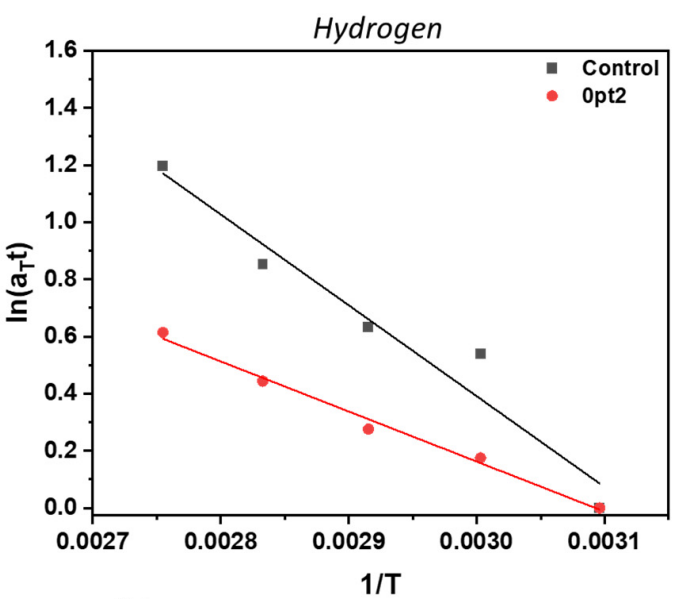

(b)

Figure A5. Validity of the TTS model for mass spectrometry data, where $\ln \left(\mathrm{a}_{\mathrm{T}} \mathrm{t}\right)$ and $\frac{1}{\mathrm{~T}}$ display a linear relationship for (a) all evolved gases and (b) hydrogen.

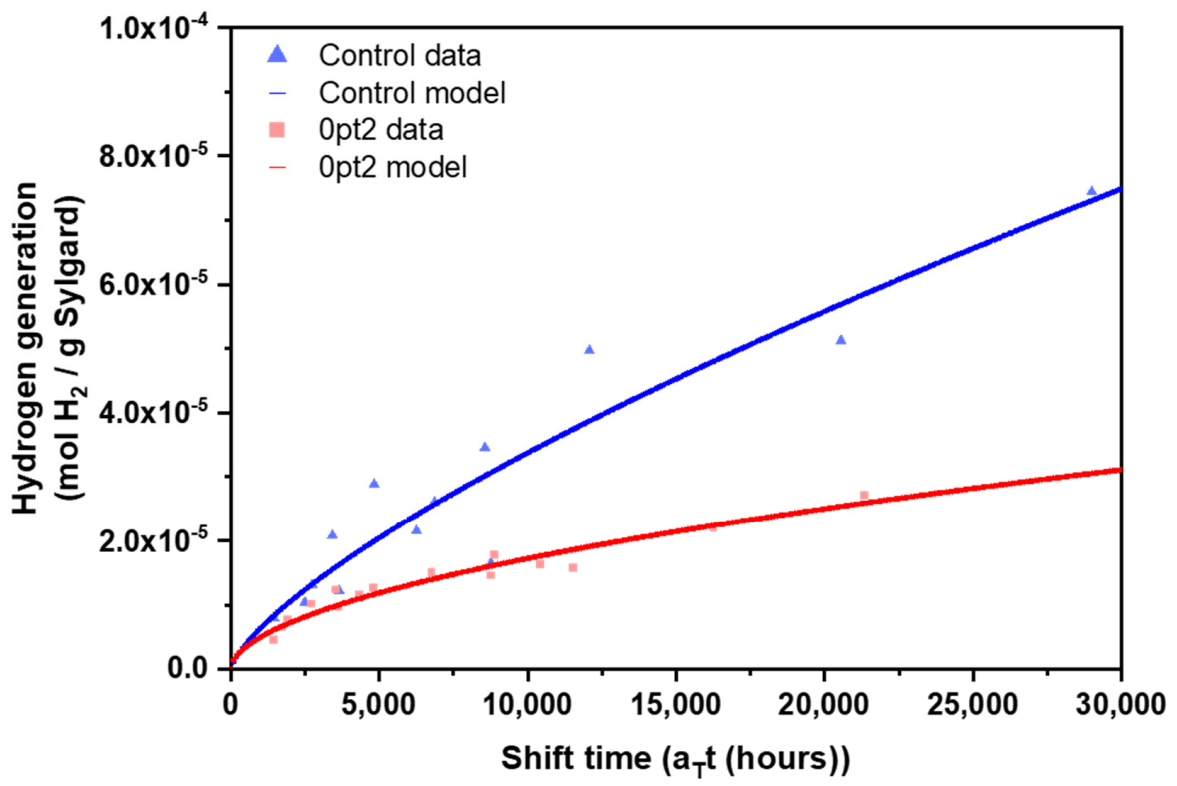

Figure A6. Hydrogen generation for the Control and 0pt2 formulations. Included is the shifted data and the model. For the Control, the equation is $\backslash\left(\mathrm{a}_{\mathrm{T}} \mathrm{t}\right)=4.22 \times 10^{-8} \mathrm{a}_{\mathrm{T}} \mathrm{t}^{0.7257}$ and for the $0 \mathrm{p} 2$, the equation is $\backslash\left(\mathrm{a}_{\mathrm{T}} \mathrm{t}\right)=1.20 \times 10^{-7} \mathrm{a}_{\mathrm{T}} \mathrm{t}^{0.5391}$. 

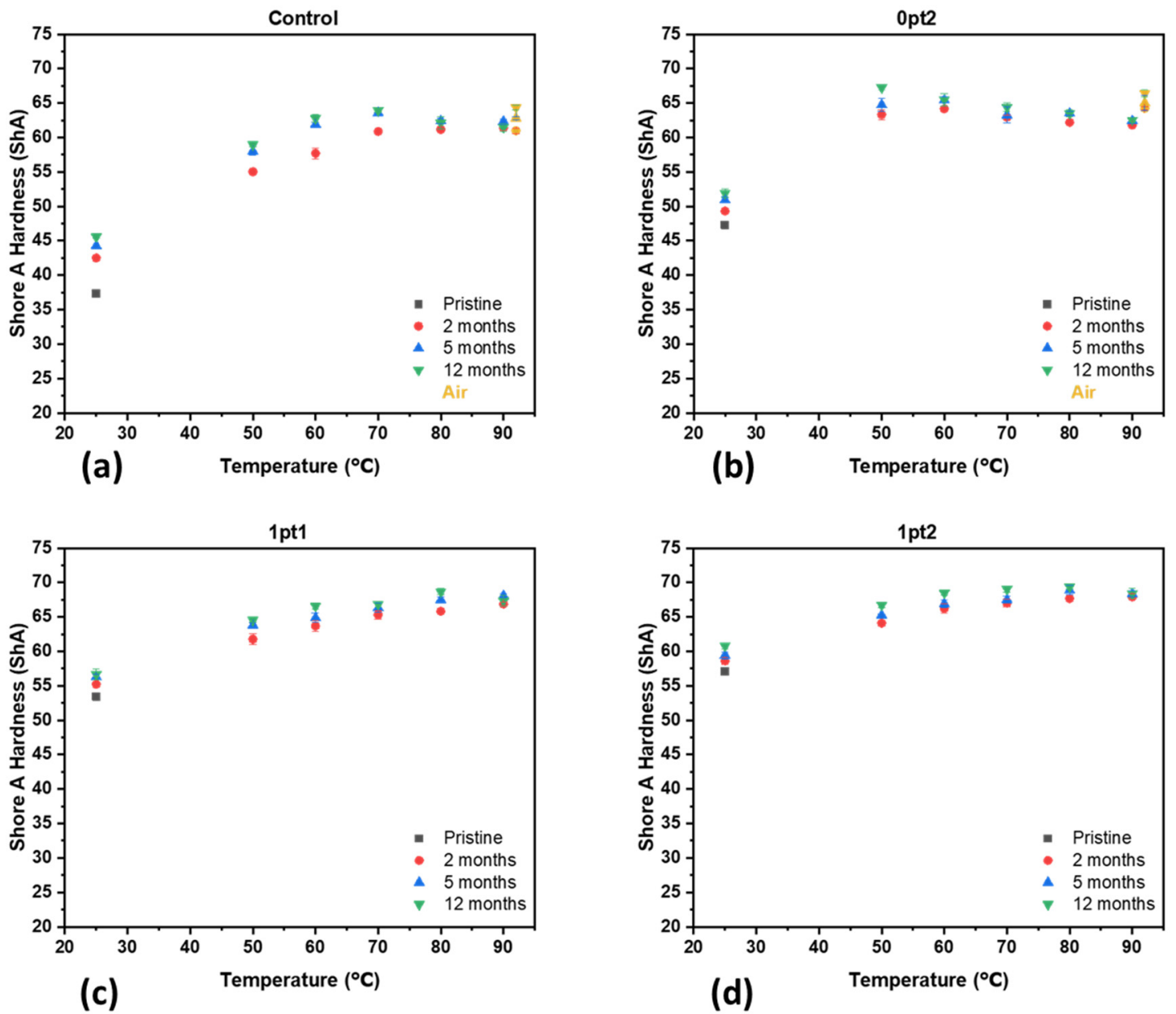

Figure A7. Shore A Hardness of thermally aged samples: (a) Controls; (b) 0pt2; (c) 1pt1; and (d) 1pt2.

$$
\operatorname{Sh} A\left(a_{T} t\right)=\frac{\operatorname{Sh} A^{\infty}}{1+e^{-k\left(a_{T} t-a_{T} t_{1 / 2}\right)}}
$$

Table A1. Time-temperature superposition Shore A Hardness master curve model parameters.

\begin{tabular}{cccc}
\hline Formulation & Final Hardness $\left(\boldsymbol{S h A}^{\infty}\right)$ & Steepness $(\boldsymbol{k})$ & Midpoint $\left(a_{T} t_{1 / 2}\right)$ \\
\hline Control & 62.73 & 0.0013 & -300 \\
\hline 0pt2 & 63.98 & 0.0020 & -525 \\
\hline 1pt1 & 67.34 & 0.0019 & -700 \\
\hline $1 \mathrm{pt} 2$ & 68.82 & 0.0015 & -1050 \\
\hline
\end{tabular}

Final hardness $S h A^{\infty}$ values were averaged over every measurement that ended up being associated with a shift time of over $9000 \mathrm{~h}$. The values presented in the table maximize $\mathrm{R}^{2}$. 


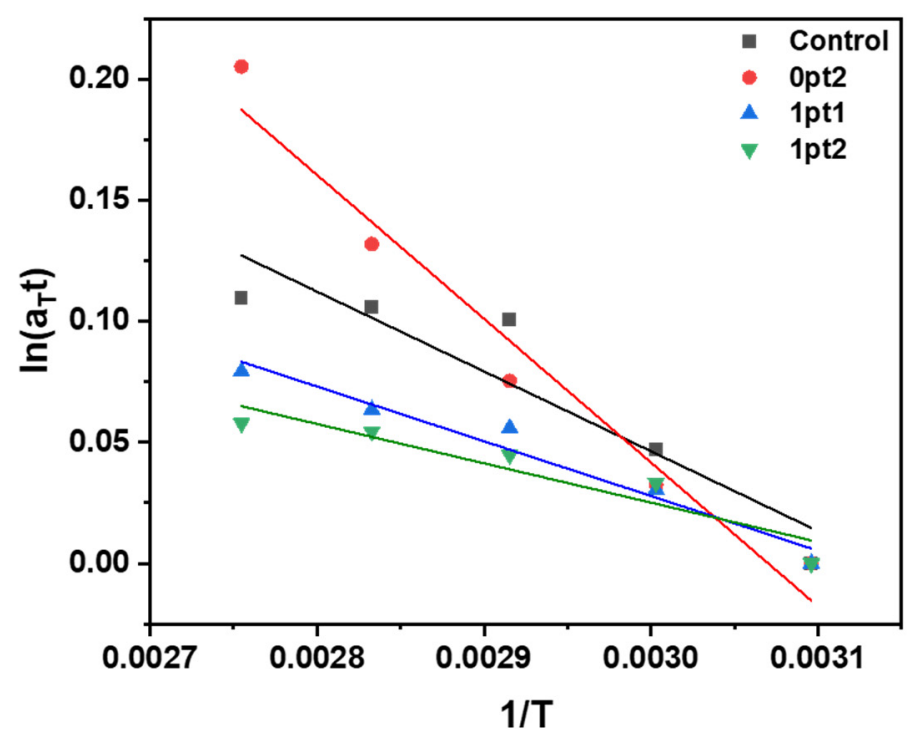

Figure A8. Validity of the TTS model for Shore A Hardness data, where $\ln \left(\mathrm{a}_{\mathrm{T}} \mathrm{t}\right)$ and $\frac{1}{\mathrm{~T}}$ display a linear relationship for all modifications.

\section{References}

1. Harley, S.J.; Glascoe, E.A.; Maxwell, R.S. Thermodynamic Study on Dynamic Water Vapor Sorption in Sylgard-184. J. Phys. Chem. B 2012, 116, 14183-14190. [CrossRef]

2. Kendrick, T.; Parbhoo, B.; White, J. Appendix to 'Siloxane polymers and copolymers'. In The Silicon-Heteroatom Bond; John Wiley \& Sons Ltd. Baffins Lane: Chichester, UK, 1991; pp. 141-150.

3. Olima, M. Mechanical Characterization of Polydimethylsiloxane. Master's Thesis, The University of Oklahoma, Parrington Oval, Normal, OK, USA, 2017.

4. Owen, M.J. Siloxane Surface Activity; American Chemical Society (ACS): Washington, DC, USA, 1989; pp. $705-739$.

5. Schneider, F.; Draheim, J.; Kamberger, R.; Wallrabe, U. Process and material properties of polydimethylsiloxane (PDMS) for Optical MEMS. Sens. Actuators A Phys. 2009, 151, 95-99. [CrossRef]

6. Lee, J.N.; Park, A.C.; Whitesides, G.M. Solvent Compatibility of Poly(dimethylsiloxane)-Based Microfluidic Devices. Anal. Chem. 2003, 75, 6544-6554. [CrossRef]

7. Henrey, M.; Tellez, J.; Wormnes, K.; Pambaguian, L.; Menon, C. Sticking in space: Manufacturing dry adhesives and testing their performance in space environments. In Proceedings of the 12th Symposium on Advanced Space Technologies in Robotics and Automation, Noordwijk, The Netherlands, 15-17 May 2013.

8. Dow, SYLGARD ${ }^{\mathrm{TM}} 184$ Silicone Elastomer Technical Data Sheet. 2017. Available online: https://www.dow.com/en-us/pdp. sylgard-184-silicone-elastomer-kit.01064291z.html (accessed on 12 September 2021).

9. Ortiz-Acosta, D. Sylgard®Cure Inhibition Characterization; Los Alamos National Lab. (LANL): Los Alamos, NM, USA, 2012.

10. Marciniec, B. Comprehensive Handbook on Hydrosilylation; Elsevier: Amsterdam, The Netherlands, 2013.

11. Hammouch, S.O.; Beinert, G.; Herz, J. Contribution to a better knowledge of the crosslinking reaction of polydimethylsiloxane (PDMS) by end-linking: The formation of star-branched PDMS by the hydrosilylation reaction. Polymer 1996, 37, 3353-3360. [CrossRef]

12. Marciniec, B. Hydrosilylation: A Comprehensive Review on Recent Advances; Springer: Dordrecht, The Netherlands, 2009.

13. Murphy, E.; Dumont, J.H.; Park, C.H.; Kestell, G.; Lee, K.; Labouriau, A. Tailoring properties and processing of Sylgard 184: Curing time, adhesion, and water affinity. J. Appl. Polym. Sci. 2020, 137, 48530. [CrossRef]

14. Gao, J.; Guo, D.; Santhanam, S.; Fedder, G.K. Material Characterization and Transfer of Large-Area Ultra-Thin Polydimethylsiloxane Membranes. J. Microelectromech. Syst. 2015, 24, 2170-2177. [CrossRef]

15. Bello, M.; Welch, C.; Goodwin, L.; Keller, J. Sylgard ${ }^{\circledR}$ Mixing Study; Los Alamos National Lab. (LANL): Los Alamos, NM, USA, 2014.

16. Eddington, D.T.; Crone, W.C.; Beebe, D.J. Development of process protocols to fine tune polydimethylsiloxane material properties. In Proceedings of the 7th International Conference on Miniaturized Chemical and Biochemical Analysis Systems, Squaw Valley, CA, USA, 5-9 October 2003.

17. Barnes, S.; Riley, S.; Wolfe, S. Hydrogen evolution from silicone resins for primary coating applications. IEE Proc. J Optoelectron. 1985, 132, 169-171. [CrossRef]

18. Liu, M.; Sun, J.; Chen, Q. Influences of heating temperature on mechanical properties of polydimethylsiloxane. Sens. Actuators A Phys. 2009, 151, 42-45. [CrossRef] 
19. Luo, X.; Mather, P.T. Preparation and Characterization of Shape Memory Elastomeric Composites. Macromolecules 2009, 42, 7251-7253. [CrossRef]

20. Ko, Y.-I.; Kim, B.-S.; Bae, J.-S.; Kim, Y.A.; Kim, I.-S. Silicone-coated elastomeric polylactide nanofiber filaments: Mechanical properties and shape memory behavior. RSC Adv. 2013, 3, 20091-20098. [CrossRef]

21. Robertson, J.M.; Torbati, A.H.; Rodriguez, E.D.; Mao, Y.; Baker, R.M.; Qi, H.J.; Mather, P.T. Mechanically programmed shape change in laminated elastomeric composites. Soft Matter 2015, 11, 5754-5764. [CrossRef]

22. Wang, C.C.; Ding, Z.; Purnawali, H.; Huang, W.M.; Fan, H.; Sun, L. Repeated Instant Self-healing Shape Memory Composites. J. Mater. Eng. Perform. 2012, 21, 2663-2669. [CrossRef]

23. Orellana, J.; Moreno-Villoslada, I.; Bose, R.; Picchioni, F.; Flores, M.; Araya-Hermosilla, R. Self-Healing Polymer Nanocomposite Materials by Joule Effect. Polymers 2021, 13, 649. [CrossRef]

24. Cui, H.P.; Song, C.L.; Huang, W.M.; Wang, C.C.; Zhao, Y. Rubber-like electrically conductive polymeric materials with shape memory. Smart Mater. Struct. 2013, 22, 55024. [CrossRef]

25. Hong, S.; Lee, H.; Lee, J.; Kwon, J.; Han, S.; Suh, Y.D.; Cho, H.; Shin, J.; Yeo, J.; Ko, S.H. Highly Stretchable and Transparent Metal Nanowire Heater for Wearable Electronics Applications. Adv. Mater. 2015, 27, 4744-4751. [CrossRef]

26. Gong, S.; Lai, D.; Su, B.; Si, K.J.; Ma, Z.; Yap, L.W.; Guo, P.; Cheng, W. Highly Stretchy Black Gold E-Skin Nanopatches as Highly Sensitive Wearable Biomedical Sensors. Adv. Electron. Mater. 2015, 1, 1400063. [CrossRef]

27. Lay, M.; Ramli, M.R.; Ramli, R.; Mang, N.C.; Ahmad, Z. Crosslink network and phenyl content on the optical, hardness, and thermal aging of PDMS LED encapsulant. J. Appl. Polym. Sci. 2019, 136, 47895. [CrossRef]

28. Ghosh, D.; Khastgir, D. Degradation and Stability of Polymeric High-Voltage Insulators and Prediction of Their Service Life through Environmental and Accelerated Aging Processes. ACS Omega 2018, 3, 11317-11330. [CrossRef]

29. Yeh, C.-H.; Dowland, M.; Schmidt, R.G.; Shull, K.R. Fracture and thermal aging of resin-filled silicone elastomers. J. Polym. Sci. Part B Polym. Phys. 2015, 54, 263-273. [CrossRef]

30. Labouriau, A.; Robison, T.; Meincke, L.; Wrobleski, D.; Taylor, D.; Gill, J. Aging mechanisms in RTV polysiloxane foams. Polym. Degrad. Stab. 2015, 121, 60-68. [CrossRef]

31. Labouriau, A.; Cox, J.D.; Schoonover, J.R.; Patterson, B.; Havrilla, G.; Stephens, T.; Taylor, D. Mössbauer, NMR and ATR-FTIR spectroscopic investigation of degradation in RTV siloxane foams. Polym. Degrad. Stab. 2007, 92, 414-424. [CrossRef]

32. Labouriau, A.; Cady, C.; Gill, J.; Stull, J.; Ortiz-Acosta, D.; Henderson, K.; Hartung, V.; Quintana, A.; Celina, M. Gamma irradiation and oxidative degradation of a silica-filled silicone elastomer. Polym. Degrad. Stab. 2015, 116, 62-74. [CrossRef]

33. Barnes, S.; Riley, S.; Wolfe, S. Hydrogen evolution behaviour of silicone-coated optical fibres. Electron. Lett. 1985, 21, 712-713. [CrossRef]

34. Materials Handling Guide: Hydrogen-Bonded Silicon Compounds. Developed by the Operating Safety Committees of the Silicones Environmental, Health and Safety Center (SEHSC), CES-Silicones Europe (CES), in partnership with the Silicones Industry Association of Japan (SIAJ). July 2016. Available online: https://globalsilicones.org/wp-content/uploads /2020/10/ Global-SiH-Manual.pdf (accessed on 12 September 2021).

35. Manders, W.F.; Bellama, J.M. Multiphoton infrared laser-induced degradation of polydimethylsiloxane and hexamethyldisiloxane. J. Polym. Sci. Polym. Chem. Ed. 1985, 23, 351-357. [CrossRef]

36. Grassie, N.; Macfarlane, I. The thermal degradation of polysiloxanes-I. Poly (dimethylsiloxane). Eur. Polym. J. 1978, 14, 875-884. [CrossRef]

37. Camino, G.; Lomakin, S.; Lazzari, M. Polydimethylsiloxane thermal degradation Part 1. Kinetic aspects. Polymer 2001, 42, 2395-2402. [CrossRef]

38. Thomas, T.H.; Kendrick, T.C. Thermal analysis of polysiloxanes. II. Thermal vacuum degradation of polysiloxanes with different substituents on silicon and in the main siloxane chain. J. Polym. Sci. Part A-2 Polym. Phys. 1970, 8, 1823-1830. [CrossRef]

39. Camino, G.; Lomakin, S.; Lageard, M. Thermal polydimethylsiloxane degradation. Part 2. The degradation mechanisms. Polymer 2002, 43, 2011-2015. [CrossRef]

40. Belot, V.; Corriu, R.J.P.; Leclercq, D.; Mutin, P.H.; Vioux, A. Thermal redistribution reactions in crosslinked polysiloxanes. J. Polym. Sci. Part A Polym. Chem. 1992, 30, 613-623. [CrossRef]

41. Thomas, T.H.; Kendrick, T.C. Thermal analysis of polydimethylsiloxanes. I. Thermal degradation in controlled atmospheres. J. Polym. Sci. Part A-2 Polym. Phys. 1969, 7, 537-549. [CrossRef]

42. Hukins, D.; Mahomed, A.; Kukureka, S. Accelerated aging for testing polymeric biomaterials and medical devices. Med. Eng. Phys. 2008, 30, 1270-1274. [CrossRef] [PubMed]

43. Goliszek, M.; Podkościelna, B.; Sevastyanova, O.; Fila, K.; Chabros, A.; Pączkowski, P. Investigation of accelerated aging of lignin-containing polymer materials. Int. J. Biol. Macromol. 2019, 123, 910-922. [CrossRef]

44. Celina, M.; Gillen, K.; Assink, R. Accelerated aging and lifetime prediction: Review of non-Arrhenius behaviour due to two competing processes. Polym. Degrad. Stab. 2005, 90, 395-404. [CrossRef]

45. Celina, M.; Linde, E.; Brunson, D.; Quintana, A.; Giron, N. Overview of accelerated aging and polymer degradation kinetics for combined radiation-thermal environments. Polym. Degrad. Stab. 2019, 166, 353-378. [CrossRef]

46. Celina, M.C. Review of polymer oxidation and its relationship with materials performance and lifetime prediction. Polym. Degrad. Stab. 2013, 98, 2419-2429. [CrossRef] 
47. Zheng, Z.; Xia, X.; Zeng, X.; Li, X.; Wu, Y.; Liu, J.; Zhang, L. Theoretical Model of Time-Temperature Superposition Principle of the Self-Healing Kinetics of Supramolecular Polymer Nanocomposites. Macromol. Rapid Commun. 2018, 39, e1800382. [CrossRef]

48. Li, R. Time-temperature superposition method for glass transition temperature of plastic materials. Mater. Sci. Eng. A 2000, 278, 36-45. [CrossRef]

49. Galliano, A.; Bistac, S.; Schultz, J. Adhesion and friction of PDMS networks: Molecular weight effects. J. Colloid Interface Sci. 2003, 265, 372-379. [CrossRef]

50. Büyüktanir, E.A.N.; Küçükyavuz, Z. Solution properties of poly (dimethyl siloxane). J. Polym. Sci. Part B Polym. Phys. 2000, 38, 2678-2686. [CrossRef]

51. Morariu, S.; Brunchi, C.E.; Cazacu, M.; Bercea, M. The Behavior of Poly(dimethylsiloxane-co-diphenylsiloxane)s in Good and Theta Solvents. J. Chem. Eng. Data 2011, 56, 1468-1475. [CrossRef]

52. Chassé, W.; Lang, M.; Sommer, J.-U.; Saalwächter, K. Cross-Link Density Estimation of PDMS Networks with Precise Consideration of Networks Defects. Macromolecules 2012, 45, 899-912, Erratum in 2015, 48, 1267-1268. [CrossRef]

53. Valentín, J.L.; González, J.C.; Mora-Barrantes, I.; Chassé, W.; Saalwächter, K. Uncertainties in the Determination of Cross-Link Density by Equilibrium Swelling Experiments in Natural Rubber. Macromolecules 2008, 41, 4717-4729. [CrossRef]

54. Muramoto, A. Studies on the Interaction Parameter in Polysiloxane Solutions. Polym. J. 1970, 1, 450-456. [CrossRef]

55. Horkay, F.; Hecht, A.-M.; Geissler, E. Thermodynamic interaction parameters in polymer solutions and gels. J. Polym. Sci. Part B Polym. Phys. 1995, 33, 1641-1646. [CrossRef]

56. Bueche, A.M. Interaction of polydimethylsiloxanes with swelling agents. J. Polym. Sci. 1955, 15, 97-103. [CrossRef]

57. Favre, E. Swelling of crosslinked polydimethylsiloxane networks by pure solvents: Influence of temperature. Eur. Polym. J. 1996, 32, 1183-1188. [CrossRef]

58. Dimitriyev, M.S.; Chang, Y.-W.; Goldbart, P.M.; Fernández-Nieves, A. Swelling thermodynamics and phase transitions of polymer gels. Nano Futur. 2019, 3, 042001. [CrossRef]

59. Pacios, I.E.; Molina, M.J.; Gómez-Antón, M.R.; Piérola, I.F. Correlation of swelling and crosslinking density with the composition of the reacting mixture employed in radical crosslinking copolymerization. J. Appl. Polym. Sci. 2006, 103, 263-269. [CrossRef]

60. Oh, K.S.; Oh, J.S.; Choi, H.S.; Bae, Y.C. Effect of Cross-Linking Density on Swelling Behavior of NIPA Gel Particles. Macromolecules 1998, 31, 7328-7335. [CrossRef]

61. Gwaily, S.; Badawy, M.; Hassan, H.; Madani, M. Influence of thermal aging on crosslinking density of boron carbide/natural rubber composites. Polym. Test. 2003, 22, 3-7. [CrossRef]

62. Lampe, F.W.; Franklin, J.L.; Field, F.H. Cross Sections for Ionization by Electrons. J. Am. Chem. Soc. 1957, 79, 6129-6132. [CrossRef]

63. Prabowo, F.; Wing-Keung, A.L.; Shen, H.H. Effect of Curing Temperature and Cross-Linker to Pre-Polymer Ratio on the Viscoelastic Properties of a PDMS Elastomer. Adv. Mater. Res. 2015, 1112, 410-413. [CrossRef]

64. Johnston, I.; McCluskey, D.; Tan, C.K.L.; Tracey, M. Mechanical characterization of bulk Sylgard 184 for microfluidics and microengineering. J. Micromech. Microeng. 2014, 24, 035017. [CrossRef]

65. Efimenko, K.; Wallace, W.E.; Genzer, J. Surface Modification of Sylgard-184 Poly(dimethyl siloxane) Networks by Ultraviolet and Ultraviolet/Ozone Treatment. J. Colloid Interface Sci. 2002, 254, 306-315. [CrossRef]

66. Hanu, L.; Simon, G.; Cheng, Y.-B. Thermal stability and flammability of silicone polymer composites. Polym. Degrad. Stab. 2006, 91, 1373-1379. [CrossRef]

67. Johnson, R., Jr.; Biefeld, R.; Sayre, J. High-temperature electrical conductivity and thermal decomposition of Sylgard ${ }^{\circledR} 184$ and mixtures containing hollow microspherical fillers. Polym. Eng. Sci. 1984, 24, 435-441. [CrossRef]

68. Rucigaj, A.; Krajnc, M.; Sebenik, U. Kinetic study of thermal degradation of polydimethylsiloxane: The effect of molecular weight on thermal stability in inert atmosphere. Polym. Sci. 2017, 3, 9.

69. Planes, M.; Le Coz, C.; Soum, A.; Carlotti, S.; Rejsek-Riba, V.; Lewandowski, S.; Remaury, S.; Solé, S. Polydimethylsiloxane/Additive Systems for Thermal and Ultraviolet Stability in Geostationary Environment. J. Spacecr. Rocket. 2016, 53, 1128-1133. [CrossRef]

70. Örn, A. Degradation Studies on Polydimethylsiloxane. Master's Thesis, Åbo Akademi University, Turku, Finland, 2019.

71. Liu, J.; Zong, G.; He, L.; Zhang, Y.; Liu, C.; Wang, L. Effects of Fumed and Mesoporous Silica Nanoparticles on the Properties of Sylgard 184 Polydimethylsiloxane. Micromachines 2015, 6, 855-864. [CrossRef]

72. Müller, A.; Wapler, M.C.; Wallrabe, U. A quick and accurate method to determine the Poisson's ratio and the coefficient of thermal expansion of PDMS. Soft Matter 2019, 15, 779-784. [CrossRef]

73. Kong, K.; Mariatti, M.; A.Rashid, A.; Busfield, J. Enhanced conductivity behavior of polydimethylsiloxane (PDMS) hybrid composites containing exfoliated graphite nanoplatelets and carbon nanotubes. Compos. Part B Eng. 2014, 58, 457-462. [CrossRef]

74. Rücker, C.; Kümmerer, K. Environmental Chemistry of Organosiloxanes. Chem. Rev. 2015, 115, 466-524. [CrossRef]

75. Ducom, G.; Laubie, B.; Ohannessian, A.; Chottier, C.; Germain, P.; Chatain, V. Hydrolysis of polydimethylsiloxane fluids in controlled aqueous solutions. Water Sci. Technol. 2013, 68, 813-820. [CrossRef]

76. West, J.K. Theoretical analysis of hydrolysis of polydimethylsiloxane (PDMS). J. Biomed. Mater. Res. 1997, 35, 505-511. [CrossRef]

77. Venkatachalam, S.; Hourlier, D. Heat treatment of commercial Polydimethylsiloxane PDMS precursors: Part I. Towards conversion of patternable soft gels into hard ceramics. Ceram. Int. 2019, 45, 6255-6262. [CrossRef]

78. Bahloul-Hourlier, D.; Latournerie, J.; Dempsey, P. Reaction pathways during the thermal conversion of polysiloxane precursors into oxycarbide ceramics. J. Eur. Ceram. Soc. 2005, 25, 979-985. [CrossRef] 
79. Antosik, A.K.; Bednarczyk, P.; Czech, Z. Aging of silicone pressure-sensitive adhesives. Polym. Bull. 2017, 75, 1141-1147. [CrossRef]

80. McIntosh, K.; Cotsell, J.; Cumpston, J.; Norris, A.; Powell, N.; Ketola, B. The Effect of Accelerated Aging Tests on the Optical Properties of Silicone and EVA Encapsulants. In Proceedings of the 24th European Photovoltaic Solar Energy Conference, Hamburg, Germany, 21-25 September 2009; pp. 3475-3482.

81. Cifter, E.D.; Ozdemir-Karatas, M.; Cinarli, A.; Sancakli, E.; Balik, A.; Evlioglu, G. In vitro study of effects of aging and processing conditions on colour change in maxillofacial silicone elastomers. BMC Oral Health 2019, 19, 122. [CrossRef]

82. Gary, J.J.; Smith, C.T. Pigments and their application in maxillofacial elastomers: A literature review. J. Prosthet. Dent. 1998, 80, 204-208. [CrossRef] 